NBS

UBLICATIONS NBSIR 81-2428

\title{
Communication Systems for Disabled Users of Buildings
}

U.S. DEPARTMENT OF COMMERCE

National Bureau of Standards

National Engineering Laboratory

Center for Building Technology

Building Physics Division

Washington, DC 20234

December 1981

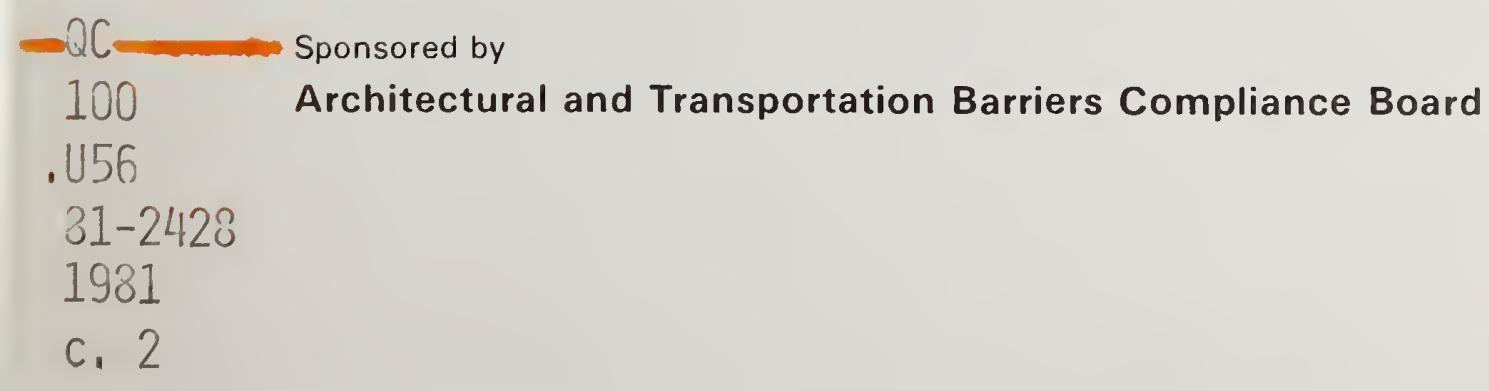



,...

COMMUNICATION SYSTEMS FOR DISABLED USERS OF BUILDINGS

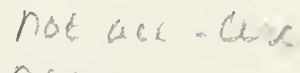

Belinda L. Collins

William F. Danner

Robert L. Tibbott

U.S. DEPARTMENT OF COMMERCE

National Bureau of Standards

National Engineering Laboratory

Center for Building Technology

Building Physics Division

Washington, DC 20234

December 1981

Sponsored by

Architectural and Transportation Barriers Compliance Board

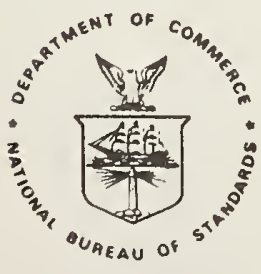

U.S. DEPARTMENT OF COMMERCE, Malcolm Baldrige, Secretary NATIONAL BUREAU OF STANDARDS. Ernest Ambler, Director 


$$
\begin{aligned}
& \text { * } 3 x+3
\end{aligned}
$$

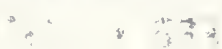




\begin{abstract}
Communication systems in buildings are designed to provide both emergency and directional information to all building users. Yet such systems, which are typically comprised of visual signs and audible alarms, may fail to reach some of the estimated twenty-seven million hearing or vision impaired people in the United States. As a result, a number of alternative communication systems have been proposed for inclusion in accessibility guidelines. In the following pages the research base underlying communication provisions for each of three sensory modalities, vision, hearing and touch, are reviewed. In addition, various proposed code recommendations are presented and discussed. The adequacy of the research base for each provision is discussed along with the need for various code provisions. It is noted that code provisions for tactile warnings and exit markings are particularly inadequate. Recommendations for further research into tactile warnings, tactile signage, and visual alarms are suggested.
\end{abstract}

Key Words: accessibility; alarms; blind; communication; code requirements; deaf; directional indicators; handicapped users; tactile warnings. 


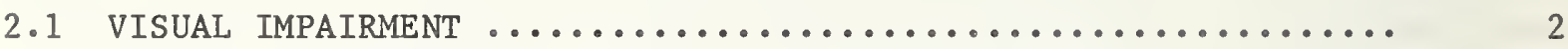

2.1 .1 Definitions and Extent of Visual Impairment .......... 2

2.1 .2 Types of Visual Impairment ..................... 3

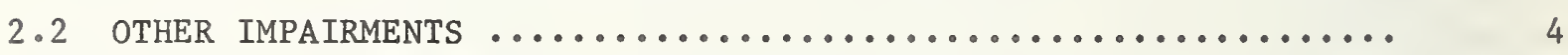

2.3 EVALUATION OF PROVISIONS FOR VISUAL COMMUNICATION SYSTEMS .... 4

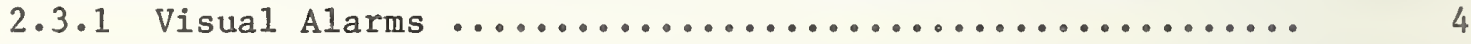

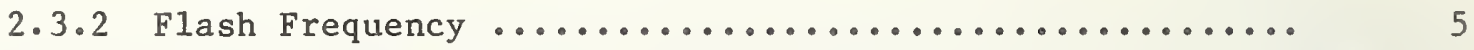

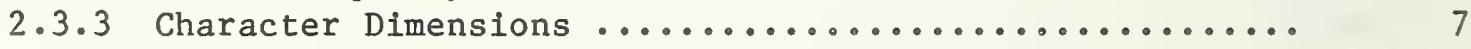

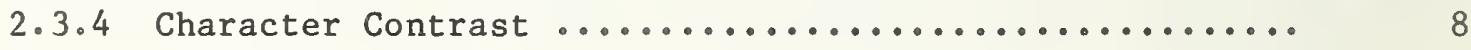

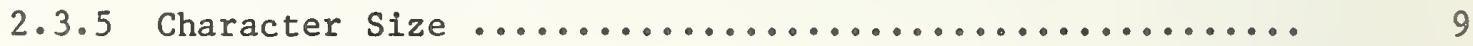

2.3 .6 Sign Location ............................ 10

2.4 CONCLUSIONS AND SUGGESTIONS FOR FURTHER RESEARCH .......... 10

3. INTRODUCTION TO AUDITORY COMMUNICATION REQUIREMENTS ........... 12

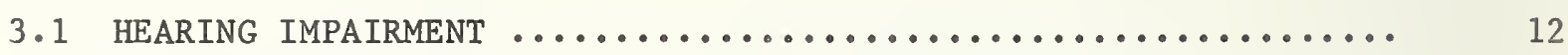

3.1 .1 Definitions and Extent of Hearing Impairment ......... 12

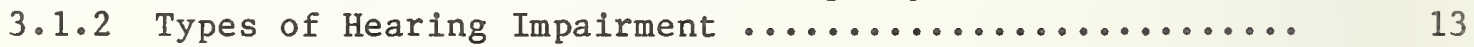

3.1 .3 Other Impairments ........................... 14

3.2 EVALUATION OF PROVISIONS FOR AUDITORY COMMUNICATION SYSTEMS .. 14

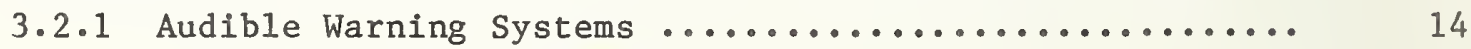

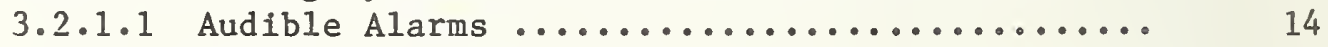

3.2 .1 .2 Appendix to Audible Alarms .............. 17

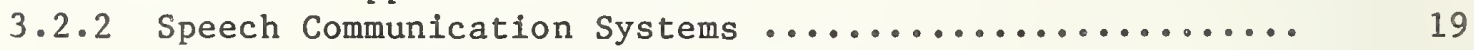

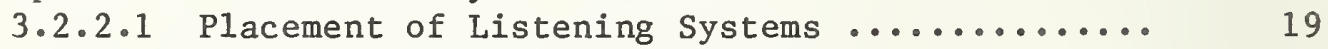

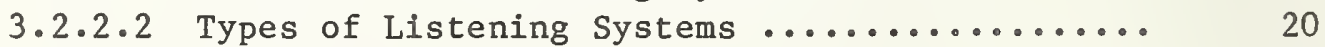

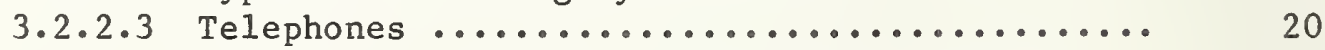

3.2.2.4 Appendix to Placement of Listening Systems ... 20

3.2 .2 .5 Appendix to Types of Listening Systems ...... 21

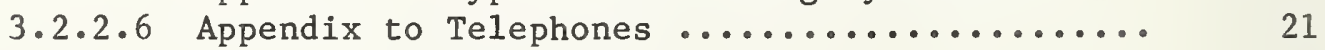

3.2.3 Sound Reinforcement Systems ................... 22

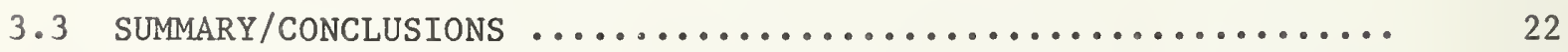

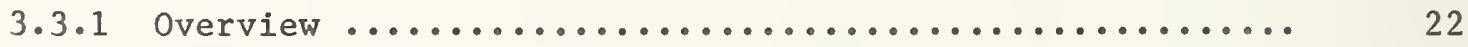

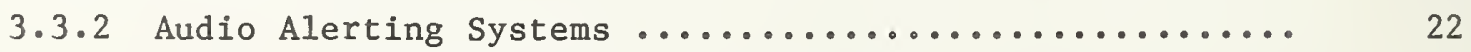

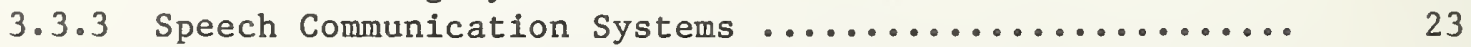

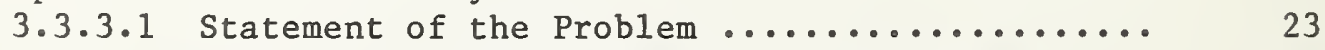

3.3.3.2 Approach to Speech Communication Systems ..... 24

3.3.3.3 Economic Considerations ............... 26 
3.4 FURTHER RESEARCH $\ldots \ldots \ldots \ldots \ldots \ldots \ldots \ldots \ldots \ldots \ldots \ldots \ldots \ldots \ldots \ldots \ldots \ldots$

4. INTRODUCTION TO TACTILE COMMUNICATION REQUIREMENTS ............ 28

4.1 CODE REQUIREMENTS .............................. 28

4.2 TACTILE WARNINGS ON HORIZONTAL SURFACES ............... 33

4.3 DIRECTIONAL AND INFORMATIONAL CUES .................. 37

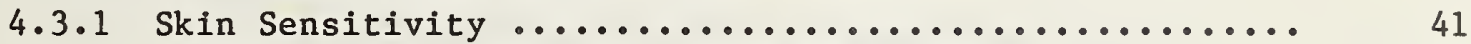

4.3.2 Visual Impairments and Tactile Sensitivity .......... 42

4.3 .3 Braille Sensitivity ......................... 43

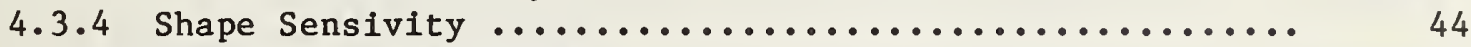

4.3 .5 Tactile Door Markings ....................... 48

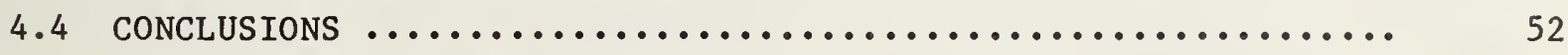

4.5 TACTILE RESEARCH NEEDS $\ldots \ldots \ldots \ldots \ldots \ldots \ldots \ldots \ldots \ldots \ldots \ldots \ldots \ldots \ldots$

5. CONCLUSIONS $\ldots \ldots \ldots \ldots \ldots \ldots \ldots \ldots \ldots \ldots \ldots \ldots \ldots \ldots \ldots \ldots \ldots \ldots \ldots \ldots \ldots$

6. REFERENCES .................................... 56 
Table 1. Estimates of the Population Distribution Average Hearing Loss (AHL) at 500, 1000, and $2000 \mathrm{~Hz}$ in the Better Ear, for Four Stages of Hearing Disability Classified by Degree

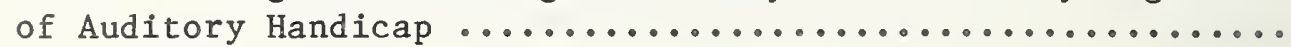

Table 2. ATBCB Part 1190 - Minimum Guidelines and Requirements for

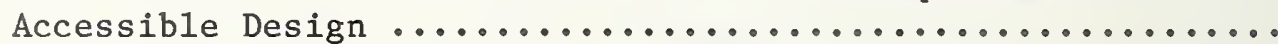

Table 3. Code Requirements for Tactile Warnings ................ 29-30

Table 4. Tactile Warnings for Horizontal Surfaces from Other Codes ... 32

Table 5. Code Requirements of Tactile Communication ............... 38

Table 6. Tactile Communication Requirements from Other Codes ........ 39

Table 7. Code Requirements for Tactile Warnings on Doors and Vertical Surfaces .................................. 49-51

Table 8. Recommended High Priority Areas for Research on Building Communication Systems for Disabled Users ............... 55

Figure 1. ANSI Al17.1 (1980) Diagram of Tactile Warning at Hazardous

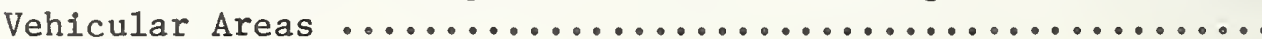


The units and conversion factors given in this table are in agreement with the International System of Units or SI system (Systeme International d'Unites). Because the United States is a signatory to the 11 th General Conference on Weights and Measures which defined and gave official status to the SI system, the following conversion factors are given.

Length

1 in $=0.0254 *$ meter

$1 \mathrm{ft}=0.3048 *$ meter

Area

1 in $^{2}=6.4516 * \times 10^{-4}$ meter $^{2}$

Illumination

$1 \mathrm{ft}$ candle $=10.76 \mathrm{lux}$

* Exact $1 y$ 


\section{FOREWORD}

The Architectural and Transportation Barriers Compliance Board (ATBCB) was created by PL 91-205, Amendments to the Architectural Barriers Act (1970). This Board is composed of the heads of, or representatives from, the following federal agencies: Departments of Health and Human Services; Education; Defense; Justice; Transportation; Housing and Urban Development; Labor; Interior; General Services Administration; United States Postal Service; and the Veteran's Administration. In addition, 11 public members, of which at least five must be handicapped individuals are appointed by the President. The Board's purpose is to ensure compliance with the Architectural Barriers Act, to conduct research related to architectural barriers, and to bring civil action in Federal court to enforce provisions of the act in any non-complying Federal department or agency. The Board is also empowered to develop minimum guidelines for accessibility. These proposed guidelines are referred to as the ATBCB rule (1981) in the following pages; and are similar to, but not identical with, the American National Standards Institute (ANSI) Al17.1 Specifications for Making Buildings and Facilities Accessible to and Usable by physically handicapped people (1980). Provisions of these two documents are discussed in detail, as they relate to communication systems for disabled users of buildings. 
Communication systems in buildings are designed to provide both emergency and directional information to all building users. Yet, such systems which typically consist of visual signs and audible alarms, may fail to communicate with vision and hearing-impaired users. As a result, a number of alternative communication systems have been proposed and incorporated into accessibility guidelines. These include tactile warnings and indicators, raised or incised alpha-numeric characters, pulsed visual alarms, high contrast signs, audible alarms, and specialized acoustic equipment. In many cases, however, the effectiveness of the proposed alerting and signaling systems has not been adequately determined for the intended user group.

In the following pages the research base for building communication system requirements for disabled users is examined in terms of three separate sensory modalities -- vision, audition, and touch. For each modality the current code provisions, specifically the ATBCB Rule (1981), the ANSI Al17.1 (1980) Specifications for Accessibility, and relevant local codes are examined. The adequacy of the research base for each provision is then discussed in some detail. Finally, conclusions for needed additional research in each area are drawn.

Throughout this report the focus will be on the properties of the built environment that are amenable to improving communications with disabled users. The many special systems available to expand the user's capabilities are outside the scope of this report and are not discussed.

Although the communication system requirements are specifically aimed at disabled users, it is important to point out that such systems can affect all building users. Requirements of populations which differ from the target population must also be considered. Tactile warnings that impede those in wheelchairs or walkers can themselves become a barrier, for example. On the other hand, provision of effective tactile egress markers could aid all building users, disabled or not, during a fire or a similar building emergency where visibility is greatly reduced. As a result, communication system requirements must be assessed for a wide spectrum of users. The potential for improving communication for all building users, while meeting the needs of specific disabled users, is great. 
Visual communication systems in buildings serve two general purposes. First, they provide orientational and instructional information regarding the interior plan or layout of a building, the location of particular rooms, activities, people, and facilities, and the operation of devices such as telephones and elevators. Information of this type is usually conveyed through the use of signs incorporating words, numbers, and symbols. Second, visual communication systems warn building users of emergency situations such as fires, generally through attention-getting devices such as flashing lights. Most visual communication systems -- whether designed to transmit emergency or nonemergency information -- make use of techniques such as color coding, brightness contrast, and standardized locations to increase their effectiveness.

In general, visual communication aids serve nearly all persons disabled or not. There are, however, within the total population of building users certain groups for which the potential benefit from the use of appropriate visual aids is great. These groups include: the visually impaired, including many persons who are legally blind; persons who are deaf or have a severe hearing impairment; developmentally disabled persons; and those who are illiterate or speak a foreign language.

\subsection{VISUAL IMPAIRMENT}

\subsubsection{Definitions and Extent of Visual Impairment}

Three degrees of visual disability may be identified (Bureau of Census, 1979):

(1) Visual impairment includes "blindness in one or both eyes, cataract, glaucoma, color blindness, detached retina or other condition of the retina, or any other trouble seeing with one or both eyes even when wearing glasses."

(2) Severe visual impairment is defined as "an inability to read ordinary newsprint with glasses using both eyes, or having no useful vision in either eye, or blindness in both eyes."

(3) Legal blindness is defined as "visual acuity for distant vision of 20/200 or less in the better eye, with best correction, or widest diameter of visual field subtending an angle of less than 20 degrees."

Using these definitions, in 1972 there were approximately 10.7 million visually impaired persons in the United States ( 5 percent of the population), 1.5 million persons with severe visual impairment ( 0.7 percent), and 468,000 persons who were legally blind (0.2 percent) (Bureau of the Census, 1979).

The age-specific incidence of severe visual impairment in the population is as follows (Murphy, 1975): 
- 4 percent of persons with severe visual impairment are under age 25

- 8 percent are between 25 and 44

- 23 percent are between 45 and 65

- 65 percent are over age 65, including 22 percent between 65 and 74 , and 43 percent over age 75 .

Only 20,000 persons with severe visual impairment are in the labor force (American Foundation for the Blind, 1975). This number represents about 1.3 percent of the number of persons with severe visual impairments and about 0.02 percent of the labor force. The data presented above suggest that age is the primary reason that most people with severe visual impairment are not in the labor force. Other possible reasons are employer prejudice against the handicapped, and the possible inability of the severely visually impaired to perform many jobs. Also, it seems plausible, in view of the very small percentage in the labor force, that existing architectural barriers, such as the lack of effective visual communication aids, might significantly contribute to the low employment figure.

Several points should be kept in mind concerning the definitions and the estimates of visual impairment. One is that most persons who are legally blind are sensitive to light, color, and form and can benefit from visual alerting. In fact, a person with $20 / 20$ visual acuity can still meet the definition of legal blindness if enough peripheral vision has been lost so that his visual field encompasses less than 20 degrees. (Certain retinal disorders do, in fact, destroy peripheral vision without affecting central visual acuity.)

Most persons who are legally blind have acquired blindness rather than congential blindness. That is, they became blind during their lives instead of having been born blind. Since only about 10 percent of blind persons use braille (persons with acquired blindess generally do not), signage designed to aid people with severe visual impairment should also include some other form of tactile communication, such as raised letters or arabic numbers.

A further problem is that the definitions of "visual impairment" and "severe visual impairment" are rather vague. For example, it is not clear at what point a person should be considered to be having "trouble" seeing, nor what "useful" vision is. Also, should persons with only minor color vision defects be classified as visually impaired?

\subsubsection{Types of Visual Impairment}

There is no single predominant cause of visual impairment but rather a number of conditions which affect vision in various ways. Visual disorders may affect far vision (e.g. myopia), peripheral vision (e.g. early stages of glaucoma), central vision (e.g. optic neuritis), contrast perception (e.g. cataracts) night vision (e.g. retinal disorders), or multiple visual functions. The fact that the visually impaired population includes persons with a wide range of visual problems suggests that there cannot be one simple solution to the question of how to optimize the design of visual alerting systems. Instead, the use of redundant visual cues (e.g., color coding, shape coding, numerical coding, and symbols) and appropriate illumination, contrast levels, and 
character size can help ensure that the message is effectively conveyed to the greatest number of persons. In this way, persons with a problem in one visual area of function (e.g., color deficiency) will still be able to use other cues which they can perceive.

\subsection{OTHER IMPAIRMENTS}

Another group of building users with special visual alerting needs is the hearing-impaired. According to Laney (1980), an estimated 17 million persons in the United States have some form of hearing impairment. of this group, 0.5 million are totally deaf. An especially critical problem is communication with deaf persons during building emergencies such as fire, when the visibility of flashing alarms can be restricted or totally obscured. It is not clear whether deaf persons with otherwise normal sensory capacities require any special visual aids for nonemergency communications.

The problem for the developmentally disabled, the illiterate, and persons who speak a foreign language is somewhat different in that conventional visual communication systems may be ineffective because of difficulties understanding a message rather than due to sensory deficits. Graphic symbols accompanied by color and shape coding can be helpful to such persons. The use of tactile cueing may also be useful to these person as well as to the visual and hearing impaired persons, and will be discussed at length in section 4 .

The section which follows examines the adequacy of existing accessibility standards for visual communication systems in meeting the needs of disabled building users, as well as those of normal persons. Architectural and Transportation Barriers Compliance Board (ATBCB) provisions for visual alerting are described briefly and compared with provisions in other standards. Research relating to the various provisions is discussed, and conclusions are presented regarding the adequacy of the provisions. Specific research directed at improving the provisions and the technical basis for them is suggested in Section 4 .

\subsection{EVALUATION OF PROVISIONS FOR VISUAL COMMUNICATION SYSTEMS}

\subsubsection{Visua1 Alarms}

If audible alarms are provided, then in addition, provide a visual alarm device adjacent to or within each exit sign which flashes in conjunction with audible alarms and operates from the same power source. (ATBCB Rule, 1981)

This provision is worded similarly to those in ANSI Al17.1 (1980), the DoD-Army Design Guide (1976), the HEW Design Guide (1978), and the Illinois Accessibility Standards (1978). The DoD-Army Design Guide and the Postal Service Standards (1979) allow rotating lights. Strobe lights and pulsating signals are forbidden in some standards (DoD, 1976; HEW, 1978). It is not clear whether or not the ATBCB wording excludes rotating lights (i.e., whether the word "flashes" refers to electrically flashed lights only or is used in a more general sense to mean "flashing lights," independent of the mechanism producing the flashes). 
A fundamental principle of visual signaling is that the conspicuity of a signal light is maximized by making that light as perceptually different as possible from its background. There is considerable evidence from laboratory studies that the use of a flashing light rather than a steadily burning one is an effective means of increasing conspicuity. Bartley (1961), for example, reported that lights which flashed at frequencies ranging from $2-20 \mathrm{~Hz}$ appeared brighter than the same lights shining steadily. Gerathewoh1 (1953, 1957) conducted a series of laboratory studies of reaction time to peripherally viewed lights and found that a flashing light was more conspicuous than a steadily burning light when the background consisted of steady lights. Crawford (1962, 1963) found, however, that the presence of flashing lights in the background decreased the conspicuity of flashing signal lights.

There have also been some studies of the conspicuity of exit signs during actual building emergencies. Wiley (1972) and Sharry (1974) conducted investigations of occupant behavior during building fires and concluded that the absence of illuminated emergency exit signs was an important factor contributing to injuries and loss of life. Other evidence suggests that some additional means of increasing conspicuity besides merely illuminating exit signs is needed. Bryan (1956), for instance, interviewed 38 survivors of a building fire. One of the questions he asked each of them was: "Did you notice if any of the doors had exit lights over them?". Bryan reported that "only 1 person stated that he knew the exit lights were on...2 persons did not know, and 2 persons thought the exit lights were on, while 33 people said they never noticed" -- including 8 of the policemen and firemen questioned.

The question of whether a flashing exit light is more conspicuous than a rotating light does not appear to have received much research attention. At a distance, it would not be expected to matter perceptually which kind of light was used, since both would probably appaar to be flashing. Under certain restricted visibility conditions such as smoke, a rotating light might be more effective, since the sweep of the beam could be seen even when a person is outside the beam. The single most important variable determining conspicuity, however, is effective intensity. Effective intensity is defined as "the intensity of a fixed light, which has the same signal effectiveness as the flashing light in question" (Illuminating Engineering Society, 1964). If a light is of sufficient effective intensity, it does not matter much, it seems, which type of light if used -- electrically flashedor rotating.

\subsubsection{Flash Frequency}

Flash frequency of visual alarms shall be less than $5 \mathrm{~Hz}$ (ATBCB, 1981)

There is agreement among those standards which specify upper limits for flash rates that $5 \mathrm{~Hz}$ is an appropriate maximum (ANSI, 1980; State of I1linois, 1978; USPS, 1979; State of Massachusetts, 1977). With respect to the technical literature on the effects of various flash rates on visual perception, the optimum flash rate is less than $20 \mathrm{~Hz}$. At rates above $20 \mathrm{~Hz}$, a flashing light begins to be perceived as steady, and when this happens, the advantages of increased conspicuity through brightness enhancement and the intermittent quality of the signal are lost. For dim lights, this fusion process may begin 
at about $15 \mathrm{~Hz}$. Gerathewohl (1953, 1957) investigated the conspicuity of flashing light signals at frequencies of $0.3,1,2,3$, and $4 \mathrm{~Hz}$ for various contrasts and flash durations. He concluded that for the conditions tested, the most conspicuous signal was one with a flash rate of $3 \mathrm{~Hz}$, provided that the light was at least twice as bright as its background. Response times to lights flashing at $0.3 \mathrm{~Hz}$ were about twice as slow as at $3 \mathrm{~Hz}$ when contrast was low. At high contrast levels, response was still nearly 40 percent slower at $0.3 \mathrm{~Hz}$ than at $3 \mathrm{~Hz}$. Since Gerathewohl's studies were limited to flash rates of between 0.3 and $4 \mathrm{~Hz}$, it is difficult to determine from his data what effect further increases in flash rate beyond $4 \mathrm{~Hz}$ would have on conspicuity.

Aside from considerations of conspicuity, flash rates of certain frequencies should not be used for visual alerting because they can increase the risk of triggering epileptic seizures and other undesirable reactions in susceptible persons. Jeavons and Harding (1975) reported data showing the incidence of adverse photoresponses in epileptic persons at various flash rates. They found that the risk was greatest at $16 \mathrm{~Hz}$; however, their most important finding for present purposes was that even flash rates as low as $5 \mathrm{~Hz}$ were associated with a substantially increased risk of adverse photoresponse. The incidence of such responses was only 2 percent at $1 \mathrm{~Hz}, 2$ percent at $2 \mathrm{~Hz}, 3$ percent at $3 \mathrm{~Hz}, 5$ percent at $4 \mathrm{~Hz}, 11$ percent at $5 \mathrm{~Hz}$, and 25 percent at $6 \mathrm{~Hz}$. Thus, an upper limit on flash frequency of 2 or $3 \mathrm{~Hz}$ instead of $5 \mathrm{~Hz}$ would seem to be safer for persons with epilepsy.

Current standards do not place a lower limit on the flash rate. However, it is reported that very slow flash rates of less than $1 \mathrm{~Hz}$ are unsatisfactory since they do not convey a sense of urgency to most people (Howett et. al., 1978). The evidence for the ineffectiveness of very low flash rates seems to come largely from the practical experiences of users rather than from formal research studies. However, Gerathewohl (1953, 1957) produced experimental evidence that response times to lights flashing at $0.3 \mathrm{~Hz}$ were much slower than to lights flashing at frequencies of $1 \mathrm{~Hz}$ or more. Most existing flashing signals have been designed for use at rates of 1-3 Hz (Howett, et al., 1978); emergency vehicles generally use warning lights with flash rates of about $1.5 \mathrm{~Hz}$.

Although it is not difficult to measure compliance with the provisions for flashing exit signs as they are currently stated, the wording of these provisions is sufficiently general that a visual alarm could comply with them yet still not fulfill its intended purpose. More detailed specifications are needed in several areas:

(1) As noted earlier, effective intensity is the most important determinant of conspicuity. Consequently, a lower limit on this quantity (minimum effective intensity) is required to ensure that the light will not be so weak that that it cannot be perceived. It is necessary to consider such factors as visibility under restricted conditions (e.g., smoke), degree of visual handicap to be to be accommodated, and maximum potential distance between the light and the persons to be warned. The light should not be so bright that it is disabling for persons sensitive to strong light (e.g., those with cataracts). 
(2) The upper limit of $5 \mathrm{~Hz}$ on flash frequency may be too high. Although available research data do not allow firm conclusions about the visual effectiveness of $5 \mathrm{~Hz}$ versus lower flash rates, existing signal lights rarely have flash rates exceeding 2 or $3 \mathrm{~Hz}$. These lower flash rates are also less likely to cause adverse photoresponses in epileptic persons.

(3) A lower limit on flash rate is desirabie. Currently, a light could filash at an extremely slow rate and still be in compliance -- even though it would not serve as an effective warning.

(4) Specifications for other variables, such as contrast, color, and flash duration, should ideally be included since they affect conspicuity to some extent. Lights used for visual alerting should contrast with the background as much as possible. Furthermore, red lights are subject to less scattering than blue lights under restricted visibiity conditions, such as smoke, and may also connote danger.

\subsubsection{Character Dimensions}

Letters and numbers on sign systems shall have a width-to-height ratio of between $3: 5$ and $1: 1$. (ATBCB Rule, 1.981)

This provision is consistent with those for alphanumeric character proportion in both the ANSI (1980) and Illinois standards (1978). At a particular viewing distance, the legibility of a character with a given width-to-height ratio -legibility being that quality of the character which allows a person to quickly and accurately identify it -- depends on the particular character being viewed and on the angle at which it is seen. The letter "I", for instance, does not require as much width as the letter " $W "$ ", while equal width and height produce optimum legibility for the letter "0". If a character is viewed at a large acute horizontal angle rather than straight on, the optimum width-to-height ratio increases (a wider character is needed). Meister and Sullivan (1969) report that for projected displays, the character width-to-height ratio should be approximately $0.75(3: 4)$, but closer to $1: 1$ if the display is to be viewed at large acute horizontal angles. Heglin (1973) reports that experimental studies have shown that the optimum width-to-height ratio for certain characters appears to be as high as $1.3: 1.0$ when the viewing angle is unfavorable. The range of width-to-height ratios specified by the ATBCB [4] appears reasonable provided that signage is located such that it can be viewed at an angle close to perpendicular.

Letters and numbers on sign systems shall have a stroke width-to-height ratiol of between $1: 5$ and $1: 10$. (ATBCB, 1981)

ANSI Al17.1 (1980) also specifies a stroke-width-to-height ratio of between 1.5 and $1: 10$; Illinois (1978) requires that the ratio be between $1: 6$ and $1: 10$.

1 This term should be changed to either "stroke-width-to-height ratio" or "strokewidth-to-height ratio." When "stroke" and "width" are two separate words without a hyphen, the term appears to mean the width-to-height ratio of the stroke itself instead of the ratio of the stroke's width to the letter height. 
Meister and Sullivan (1969) and Heglin (1973) recommend that ratios of between $1: 6$ and $1: 10$ be used.

The optimum stroke-width-to-height ratio varies as a function of several parameters -- primarily contrast, illumination, and character size. When positive contrast is used (1ight characters on a dark background), a narrower stroke width is required than when negative contrast is used (dark characters on a light background). This is even more true when there is a visually impaired observer or when less than optimum viewing conditions are present, such as dust or smoke between the observer and the sign. The effect of these circumstances is to increase the apparent dispersion of the light areas of the sign into the dark areas, thus making the light areas appear larger than they actually are. When high contrasts are maintained between the characters and their background, Heglin (1973) recommends stroke-width-to-height ratios of $1: 6$ to $1: 8$ for black on white and $1: 8$ to $1: 10$ for white on black. When contrast values are low, as they would be if the reflectances of sign colors differed much from those of black and white, a stroke-width-to-height ratio of about $1: 5$ should be used (1973). Similarly, as illumination is decreased, thick letters (1:5) become more readable than thin ones, regardless of whether contrast is positive or negative. For illuminated characters on a dark background, Meister and Sullivan (1969) and Heglin (1973) report that thinner strokes (ratios of $1: 8$ to $1: 10$ ) should be used. When the characters on a sign are small or must be seen at a great distance so that the visual angle is small, relatively thicker letters and numbers are required (Meister and Sullivan, 1969). Heglin (1973) recommends a stroke-width-to-height ratio of $1: 5$ to $1: 6$ under such conditions.

The range of ratios specified by the $А$ TBCB (1981) is generally consistent with those recommended by researchers in the field. However, since the optimum stroke-width-to-height ratio varies considerably for different viewing conditions, more detailed specifications of ratios might be desirable. It should be made explicit, for instance, that ratios at the $1: 5$ end of the range should be used for restricted viewing conditions (low contrast, low illumination levels, reduced character size) and for signs using negative contrast, while ratios at the $1: 10$ end of the range should be used when optimum viewing conditions are present or positive contrast is used. When the characters on a sign are small or must be seen at a great distance so that the visual angle is small, relatively thicker letters and numbers are required (Meister and Sullivan, 1969). Heglin (1973) recommends a stroke-width-to-height ratio of $1: 5$ to $1: 6$ under such conditions.

\subsubsection{Character Contrast}

Letters and numbers on sign systems shall contrast in value with their backgrounds, preferably light letters on a dark background (ATBCB, 1981).

This provision is worded very similarly to those in other guides and standards (ANSI, 1980; DoD, 1976; HEW, 1978; Illinois, 1978). As mentioned earlier, contrast may be either positive or negative. For visual tasks involving prolonged reading of text, it has been found (Tinker, 1963) that black on white (negative contrast) is more effective. However, some studies have shown that for visual 
tasks involving primarily detection, positive contrast leads to faster and more accurate response (Bishop and Crook, 1961; Hilgendorf and Milenski, 1974; Wagner, 1975).

The brightness contrast between characters and background is a potentially more effective coding dimension than the hue contrast (Roth and Finkelstein, 1968). However, redundant visual coding using both hue contrast and brightness contrast can enhance performance beyond what can be achieved by using either coding dimension by itself. McLean (1965), for instance, found that adding hue contrast to brightness contrast on a speed-of-reading dial task led to faster reading times than did brightness contrast alone.

In order for the current provision to be enforceable, the terms "light", "dark", and "contrast" must be quantitatively defined. This could be accomplished by specifying that there be a certain minimum ratio between the luminous reflectances of the characters and their background. Restrictions on the combinations of colors allowed for characters and background would help ensure that signs could be read easily by color deficient persons.

Letters and numbers on sign systems shall have a matte finish on a matte finish background (ATBCB, 1981).

The problem of glare is usually touched upon only briefly, if at all, in accessibility standards. Illinois (1978), for instance, states that "signs shall have glare free surfaces which will not interfere with legibility." It further noted that increased illumination levels to aid the visually impaired can also increase glare from highly reflective surfaces.

Defining the term "matte" in such a way that it would be susceptibie to quantitative determination could strengthen the enforceability of this provision. This would involve specifying limits for diffuse and specular surface reflectance. There has been relatively little research on quantifying the visual impact of reflections from specular surfaces (IES, 1981). One possible approach to the problem would be to specify levels of illumination in sign areas in terms of Equivalent Sphere Illumination (ESI). That is, require that lighting environments produce task visibility equivalent to that produced by a particular level of illumination in a reference sphere. This approach is discussed in detail in the IES Lighting Handbok (1981).

\subsubsection{Character Size}

Current ATBCB signage requirements state (1981), "Provide numbers and letters that are between $5 / 8$ inch $(16 \mathrm{~mm}$ ) and 2 inches $(50 \mathrm{~mm}$ ) high." Since these requirements apply to raised or incised letters, which may serve as either a visual or a tactile means of communication, both minimum and maximum heights are necessary. For visual alerting purposes, however, only the minimum character height is of concern. The $\triangle \mathrm{ABCB}$ requirements also specify minimum character heights of $1 / 2$ inch (13 mm) and 2 inches (50 mm) for elevator car position indicators and door jamb markings, respectively. The 5/8 inch (16 mm) minimum height for raised or incised characters is generally consistent with other accessibility standards (ANSI, DHEW, Illinois, USPS) although slightly higher 
and lower values are also found. For example, (1/2 inch (13 mm) is used by Ohio (1977) and 3/4 inch (19 mm) by New Jersey (1977)).

The crucial questions to be asked here are, "What is the intended viewing distance?", and "What degree of visual disability is to be provided for?". Under good illumination, characters $5 / 8$ inch ( $16 \mathrm{~mm}$ ) high can be read at a distance of approximately 37 feet $(11 \mathrm{~m})$ by a person with normal $(20 / 20)$ visual acuity. A person with $20 / 40$ vision would need to be about 18 feet ( $5.5 \mathrm{~m}$ ) from the sign before he could read it, and a person with 20/200 vision (bordering on legal blindness) would have to be about 3.7 feet $(1.1 \mathrm{~m}$ ) from the sign. Even though this latter distance seems rather close, it is still further away than necessary for tactile perception of the sign message, and would allow for visual perception by all but the most severely visually disabled persons.

\section{3 .6 Sign Location}

The ATBCB requirements specify that interior signage be located on the latch side of the door ${ }^{2}$ at a height of between 4 feet 6 inches and 5 feet 6 inches $(1.4 \mathrm{~m}$ and $1.7 \mathrm{~m}$ ) above the floor. This range is similar to those found in other accessibility standards. ANSI Al17.1 (1980) does not specify sign locations, while the DoD (1976) and Postal Service standards (1979) specify ranges of 3 feet 4 inches to 4 feet 4 inches and 3 feet 6 inches to 4 feet 6 inches $(1.0 \mathrm{~m}$ to $1.3 \mathrm{~m}$ and $1.1 \mathrm{~m}$ to $1.4 \mathrm{~m}$ ), respectively. For visual purposes, signs should ideally be located perpendicular to the viewer's normal line of sight. Significant deviations in viewing angle in either the horizontal and vertical direction exceeding about 30 degrees and 10 degrees, respectively, can decrease sign effectiveness (Meister and Sullivan, 1969; Heglin, 1973; Sorenson, 1979). Locating signage within these viewing angle limits is also desirable to accommodate persons with restricted head movement or peripheral vision. The sign heights specified by the ATBCB would appear to allow most persons to view the signs at a viewing angle within desirable limits.

\subsection{CONCLUSIONS AND SUGGESTIONS FOR FURTHER RESEARCH}

Existing accessibility standards could be improved by providing more detailed, quantitative specifications in several areas. These areas include:

- Establishing minimum values for the effective intensity and flash rate of exit signs. A lower maximum flash rate should also be considered.

- Specifying stroke-width-to-height ratios in terms of expected viewing conditions when possible.

- Quantitatively defining the terms "1ight" and "dark" as they are used in connection with sign contrast.

2 More precise wording is desirable here. The phrase "latch side of the door" should be replaced by "side of the door that opens first (or closes last)," because swinging doors and sliding doors do not always have latches. 
Restricting color combinations used on signs to avoid loss of contrast for the color deficient.

- Specifying quantitative limits for specular reflectance of sign surfaces (gloss).

Some topics needing further research are:

- How do disabled persons behave during building emergencies?

- What criteria and methods of study should be used to evaluate the effectiveness of visual communication systems for the disabled? How do flash rate, flash duration, color, and location combine to influence conspicuity of visual alarms under normal and adverse viewing conditions?

- What is the best way of alerting deaf persons during building emergencies?

- What are the effects of energy-efficient light sources on the perception of sign color by normal and visually impaired persons? What is the visual impact of various amounts of glare on visually impaired persons?

- What combinations of redundant visual cues are the most effective (e.g., color, shape, and numerical coding)?

- What are optimum levels of illumination for sign areas for visually impaired persons?

- What combinations of sensory cues (visual, auditory, tactile) are most effective for the entire disabled population? 
Although auditory communication systems in buildings are used for both emergency and non-emergency situations, an individual. with a hearing impairment may not be able to use them. The types of systems of concern for the hearing-impaired can be viewed in three general categories; (1) warning systems (alarms) which are primarily for emergency alerting purposes, (2) distributed speech communication ("public address") systems which can serve both emergency and nonemergency functions, and (3) sound reinforcement systems which are used to amplify and project speech and music over a specific audience area. Though the degrees of fidelity required by speech communication systems and sound reinforcement systems may differ, the principles applied to achieve a requisite degree of speech intelligibility are similar. Therefore, major emphasis will be placed on the discussion of speech communication systems, with several brief comments pertaining to sound reinforcement.

The first category, warning systems or "alarms", has as its primary function, the task of alerting building occupants that some dangerous condition exists. In setting standards for such systems the needs of the hearing-impaired individuals must be taken into account. One must determine whether or not most individuals can in fact hear the alarm, and estimate to what extent such auditory alarms must be supplemented by visual alarms and/or speech communication systems.

The second and third categories, however, are more complicated because more than mere detection of a warning sound is required. Information must be conveyed to the listener. The degree of accuracy achieved in this transmission serves as the criterion for the system.

Improvements in speech communication systems can benefit nearly all building users since improvements in transmission qualities required for hearing-impaired individuals tend to enhance the quality of such systems for non-impaired individuals as well. Therefore, it seems quite reasonable that standards developed for public use systems could benefit from technical consideration of the requirements for communicating with hearing-impaired individuals.

\subsection{HEARING IMPAIRMENT}

\subsubsection{Definitions and Extent of Hearing Impairment}

Hearing impairments identified during audiological examinations are stated by comparison (in decibels, dB) to the standard reference zero, IS0 389-1975(E), which specifies the "normal" threshold of hearing as a function of frequency. For convenience, hearing impairments are given a single number representation as an average hearing loss (AHL) which is the arithmetic average of the losses, expressed in decibels above standard zero, at 500,1000 , and $2000 \mathrm{~Hz}$, the frequencies most important for speech intelligibility.

Estimates of the extent of the population affected by hearing impairments (Plomp, 1978) taken from five U.S. National Health Surveys (NCHS 1965, 1967, 1970 , 1975, a,b) suggest that 7.5 percent or approximately 17 million persons 
in the U.S. experience hearing difficulties. (For a review of population estimates of hearing-impaired individuals, see Laney, 1980.) Four degrees of hearing impairments identified by Beasley (1940) were examined by Plomp. A summary of this study appears as table 1 .

Table 1. Estimates of the Population Distribution Average Hearing Loss (AHL) at 500, 1000, and $2000 \mathrm{~Hz}$ in the Better Ear, for Four Stages of Hearing Disability Classified by Degree of Auditory Handicap (After Plomp, 1978).

\begin{tabular}{|c|l|c|c|}
\hline STAGE & UNDERSTANDING SP EECH & AHL $(\mathrm{dB})$ & POPULATION IMPACTED \\
\hline 1 & Noisy Environments & $24-34$ & $4.1 \%(\sim 9.3$ million* $)$ \\
3 & $\begin{array}{l}\text { Close range conver- } \\
\text { sation in quiet } \\
\text { Loud speech without } \\
\text { hearing aid }\end{array}$ & $35-54$ & $2.4 \%(\sim 5.4$ million $)$ \\
Total deaf & $\geq 90$ & $0.2 \%(\sim 0.5$ milion $)$ \\
\hline
\end{tabular}

* Based on population of 226 million.

Although persons of all ages can be affected by such hearing impairments, the incidence and severity clearly increase with age. Plomp estimates that the number of persons affected by each of the first three stages of hearing loss doubles in the following fashion: stage 1 every 10 years from 1 percent of the population at age 20; stage 2 every 7 years from 1 percent of the population at age 50; and stage 3 every 5 years from 1 percent of the population at age 65 . This increase in the number of persons experiencing such hearing disabilities is in addition to the gradual loss of high frequency hearing with age (presbycusis) that impacts nearly twenty-five percent by age 65 and fifty percent by age 75 (Duquesnoy and Plomp, 1980).

\subsubsection{Types of Hearing Impairment}

Hearing losses, among the 17 million persons with greater than $24 \mathrm{~dB} A H L$, have two additive components (Plomp, 1978). The first component has been classified by Plomp as a class-A or attentuation loss which can be compensated for wholly or in part by hearing aids. The amplification improves speech perception in quiet environments that are not highly reverberant. The second component, however, is classified as a class-D or distortion loss which cannot be compensated for by hearing aids. Further, because of a significant decrement in resolution, the impairment makes the individual particularly susceptible to excess noise and reverberation in rooms. 
The consequence of the above for hearing-impaired individuals is that without special attention to matters of architectural acoustics or alternative remedial measures, a significant portion of the population experiences difficulties in understanding speech in public building spaces.

\subsubsection{Other Impairments}

Another group of building users for whom auditory communication systems are of particular interest is those who are visually handicapped. Though this group of individuals would typically not have specific auditory requirements in terms of detection (alarms) or speech intelligibility (speech communication sytems), they could benefit from adoption of a standardized, easily recognizable alarm signal indicating that an emergency situation has arisen. This topic will be discussed later.

The section which follows examines the adequacy of existing accessibility standards for auditory communication systems in meeting the needs of individuals with a communicative handicap. ATBCB provisions for auditory alerting and communication are described briefly and research relating to various provisions is discussed. Research directed at improving the provisions and providing technical bases for these provisions is then outlined briefly.

\subsection{EVALUATION OF PROVISIONS FOR AUDITORY COMMUNICATION SYSTEMS}

The most significant formal statement to the inclusion of requirements for physically handicapped individuals in building practices is the American National Standard Specifications for Making Buildings and Facilities Accessible to and Useable by Physically Handicapped People (ANSI A117.1-1980). The provisions of ATBCB's Minimum Guidelines and Requirements for Accessible Design (Part 1190) are nearly identical. Though California and Nevada building codes also include specifications for auditory communication systems, they do not differ significantly from ANSI Al17.1 (1980). Thus, their provisions will not be discussed individually. Rather, this document reviews only those sections of ANSI A117.1 (1980) relevant to auditory communication systems.

Relevant sections of ATBCB Part 1190 appears in brackets, and are listed in their entirety as table 2 .

\subsubsection{Audible Warning Systems (Alarms)}

\subsubsection{ANSI A117.1-1980, Section 4.28.2, Audible Alarms [119.0180]}

If provided, audible emergency alarms shall produce a sound that exceeds the prevailing equivalent sound level in the room or space by at least 15 decibels or exceeds any maximum sound level with a duration of 30 seconds by 5 decibels, whichever is louder. Sound levels for alarm signals shall not exceed 120 decibels. 
Table 2. ATBCB Part 1190 -- Minimum Guidelines and Requirements for Accessible Design

\subsection{Alarms.}

(b) Audible alarms. Audible alarms shall produce a sound pressure level that exceeds ambient room or space noise by 15 decibels or any maximum noise level of 30 seconds duration by 5 decibels, whichever is greater.

\subsection{Telephones.}

(d) Equipment for hearing impaired people. Telephone receivers shall generate a magnetic-field in the area of the receiver cap. Volume controls shall be provided in accordance with Subpart C -- Scope.

1190.230 Assembly areas.

(d) Listening systems. Provide assembly areas with a listening system to assist no fewer than two persons with severe hearing loss.

(1) If the listening system serves individual seats, locate such seats within 50 feet $(15 \mathrm{~m})$ of the stage or arena. Such locations shall provide a complete view of the stage or arena.

(2) Acceptable types of listening systems include, but are not limited to, audio loops and radio frequency systems. 
In general, audible warning systems should, as part of their design and installation, include consideration of the following: (1) the acoustical characteristics of the physical sound-radiating device (including power spectrum, frequency response and directivity), (2) the location and spacing of those devices, (3) the sound transmission properties of the building in which the system is to be installed, and (4) the background noise levels over which the signal must be heard. The provision dealing with audible alarms in the ANSI standard addresses only the last of these four important design considerations explicitly.

In 1975, the Committee on Hearing and Bioacoustics and Biomechanics (CHABA) of the National Academy of Sciences in response to a request from the National Fire Prevention Association (NFPA) proposed a national standard for fire-alarm characteristics. Their recommendations with regard to item four above have essentially been followed by ANSI A117.1-1980. Further, it was CHABA's recommendation that the acoustical characteristics of the signal source, considered by itself, be unspecified (item one above). This recommendation was made because the acoustical environment varies greatly from one building to the next. A suitable signal system should be selected by the building designer to "penetrate" the existing or projected background sound distribution.

Though this approach is quite reasonable in structures designed for normal hearing individuals, some explicit frequency range over which the maximum sound pressure level of a warning device is achieved should be specified to accommodate hearing-impaired individuals. This will be discussed further in the next section.

By specifying the level by which the warning signal must exceed the background, presumably at the "listener position," CHABA was also addressing items two and three above implicitly. That is, that decisions as to location and spacing of physical devices, and dealing with the sound transmission properties within the building are the responsibility of the building designer.

The approach taken by CHABA and reflected in ANSI A117.1-1980 represents a considerable improvement over recommendations like those made by the Uniform Building Code. Thus, the requirements specify only a minimum decibel level (A-weighted) at a particular distance from the device. Recommendations of this type address, only incompletely, item one and omit consideration of the placement of the sound sources and the acoustic properties of the building in which they are positioned.

A significant aspect not addressed, however, by ANSI A117.1-1980 is the minimum absolute sound pressure level required at a "listener position." Incorporation of requirements similar to British Standard 5839: Part 1, 1980 for fire alarm systems would be useful. That standard specifies a minimum A-weighted sound pressure level of $65 \mathrm{~dB}$ generally, and in those instances where the alarm must arouse sleeping persons, an $A$-weighted sound pressure level of $75 \mathrm{~dB}$ at the "listener position," with all doors closed. 


\subsubsection{Section A4.28.2 Audible Alarms}

This section appears in the appendix to ANSI A117.1-1980 and as such is not part of the ANSI Standard.

Audible emergency signals must have an intensity and frequency that can
attract attention of individuals who have partial hearing loss. People
over 60 years of age generally have difficulty perceiving frequencies
higher than $10,000 \mathrm{~Hz}$.

This provision would seem to imply that any frequency below $10,000 \mathrm{~Hz}$ of an unspecified but "sufficient" intensity would be appropriate to attract the attention of individuals who have partial hearing loss. Not surprisingly, the situation is considerably more complex.

Loss of high frequency hearing with age (presbycusis) is not limited to frequencies above $10,000 \mathrm{~Hz}$. In fact, perception of frequencies as low as 250 $\mathrm{Hz}$ has been shown to be affected (Corso, 1976). Usually losses between 250 and $1500 \mathrm{~Hz}$ are less severe, with progressively more severe losses in the region from 2000 to $8000 \mathrm{~Hz}$. This frequency dependent variation becomes more extreme with increasing age. However, for all age groups, the region between 250 and $1500 \mathrm{~Hz}$ would be a region of minimal loss.

Further, those individuals wearing hearing aids will have a specific frequency region over which their aids provide maximum gain. Two classic studies (Davis 1947 and Medical Research Council Report No. 261, 1947) recommended maximum gain over a frequency range from 750 to $4000 \mathrm{~Hz}$. Recent data on commercially available hearing aids compiled at the National Bureau of Standards for the Veterans Administration (Beck, 1980) indicates that for most types of hearing aids, maximum gain typically is present in the vicinity of $1000 \mathrm{~Hz}$, the region most important for speech intelligibility.

A third consideration with regard to frequency specification is addressed by British Standard 5839 mentioned previously (Butler, 1980). Specifically, that standard addresses the issue of attenuation of signal levels as a result of transmission within the building. Typical building partitions including brickwork, gypsum board on wooden studs, concrete and so on, have transmission loss values that increase rapidly with frequency (Lawrence, 1970). Therefore, in an effort to maximize transmission through such acoustical "obstacles", the British Standard recommends maximum acoustic output between 500 and $1000 \mathrm{~Hz}$. Unfortunately, as Butler points out, many warning devices have maximum output well above this frequency region. Since the efficiency of sound radiation from a typical source used for alarm systems increases as the square of the sound frequency, the performance at relatively low frequencies capable of passing through architectural barriers may be fairly inefficient.

With the above three dominant factors in mind, it appears that the frequency region between 750 and $1500 \mathrm{~Hz}$, although best suited as the region of maximum acoustical output for audible alarms, is probably not the region excited by most alarm systems. 
Another aspect of alarm characteristics not addressed by ANSI AI17.1-1980 is the temporal pattern of the acoustical signal. CHABA Working Group 73 (1975) in their report for NFPA, unamimously recommended adoption of a standard "temporal profile" for fire alarm signals. Working Group 73 felt that such standardization would fulfill the requirements that; (a) the signal should be evident and easily detectable, (b) should be distinctive and clearly different from a variety of other alarm systems (e.g. emergency vehicles) and (c) should present minimal problems in terms of adapting existing fire-alarm systems. Their conclusion was that for the standard fire alarm, the temporal pattern should consist of an alteration of nominal "on" and nominal "off" presented repeatedly. Specifically, they recommended that the signal should:

- . consist of two "shorts" and a "long" repeated regularly. Specifically, if the on-segment is denoted by an underlined number and the off-segment is not underlined, then the basic pattern would be:

$11 \leq 1 \leq 4$.

If the nominal duration for a segment were $1 / 2$ second, then the standard signal would be "on" a half-second, "off" a half-second, "on" a half second, "off" a half second, "on" one second, "off two seconds" and repeat. We would suggest that the nominal on-segments be between 0.4 and 0.6 seconds, and that the nominal off-segments be between 0.3 and 0.6 seconds.

The definition of the nominal "on" and "off" state for the signal is a standardization problem. We recommend that once the signal is nominally "on" it should achieve some level and fluctuate less than $2 \mathrm{~dB}$ from that sound level. Once the "on" state is terminated, the level of the signal should fall at least $10 \mathrm{~dB}$ within 0.1 seconds, and stay below that nominal "off" level until it resumes the "on" state. The transition from "off" to "on" should occur within 0.1 seconds. These measurements could be made in a free field, because, while the numerical values of "on" and "off" would be influenced by peculiarities of the acoustic environment (e.g., the local reverberation), the informative value of the signal would probably still be preserved.

(Green, et al., 1975)

It should be noted, that the temporal (and frequency) characteristics of a standardized alarm are still a matter of debate. An earlier proposal by NFPA which described a "slow whoop" siren is still preferred by some authorities. However, the idea of a temporal pattern signal seems to be gaining support. One possible modification is to specify groups of three equal short pulses, $a$ pattern compatible with bell systems.

A major source of difficulty in developing standardized audible alarms is the pronounced lack of direct empirical psychoacoustic data. This issue will be discussed further in section 3.3. However, until such time as reliable data 
are available, it would appear reasonable to make recommendations of an "informational" nature in the appendix to ANSI Al17.1-1980 based on current insights into the best approach to be taken.

It should be noted that an alarm signal following the recommended temporal and spectral characteristics above, though of importance for the entire population, would be particularly helpful in conveying information about the nature of the emergency to visually and hearing-impaired individuals and also, because of its simplicity, persons with language handicaps. This should provide motivation for increased efforts toward a well thought-out audible alarm standard.

\subsubsection{Speech Communication Systems}

ANSI Al17.1-1980 does not address speech communication systems directly. Reference is made, however, to requirements for sound systems in assembly areas under Section 4.33. Requirements for assembly areas are often based upon sound reinforcement systems for individuals free of hearing impairment. However, for the hearing-impaired, the critical objective of such systems is intelligible speech communication.

Therefore, consideration should be given to environmental requirements for speech intelligibility as well. (Note: Such data would be of use in evaluating direct unaided communication between individuals as well as communication via electroacoustic systems.)

A discussion of speech intelligibility requirements for the general population and specifically for those with hearing impairments appears in section 3.3.3, following a review of those provisions of ANSI Al17.1-1980 which address "assembly area" requirements.

\subsubsection{ANSI A117.1-1980, Section 4.33.6, Placement of Listening Systems [1190.230]}

If the listening system provided serves individual fixed seats, then such seats shall be located within 50-ft $(15-\mathrm{m})$ viewing distance of the stage or playing area and shall have a complete view of the stage or playing area.

This provision is quite reasonable and takes clear advantage of the fact that considerable non-verbal information can be attained at such viewing distances. Perhaps more importantly, however, is the fact that many hearing-impaired individuals rely upon information from visual speech perception (lipreading). Taking advantage of skills developed by the hearing-impaired to help alleviate their communicative handicaps is by far the most cost-effective approach possible and deserves emphasis.

Often, however, when sound systems are supplied in threaters and auditoria, managers of such spaces feel that the need for close proximity to the stage has been alleviated. Though this may be true for some individuals, it certainly does not serve very well the needs of many hearing-impaired members of the audience. A statement should be made indicating that both placement of 
individuals where they have good access to visual information and provision of listening systems are desirable.

3.2.2.2 ANSI A117.1-1980, Section 4.33.7, Types of Listening Systems [1190.230]

Audio loops and radio frequency systems are two acceptable types of listening systems.

Martin (1977) in a review of possible communication systems for the hearingimpaired discussed each of the listening systems mentioned by this provision.

The most widely used system is the inductive loop system. An a.c. magnetic field is produced by a loop of wire distributed in a room. A hearing aid used with this system must have an inductive pick-up coil that can be switched into operation in place of the microphone normally used with the aid. A disadvantage of the inductive loop is "overspill" or interference from other magnetic fields.

The second system listed by ANSI A117.1-1980 is the radio frequency system. This type has been used quite successfully. A more recently developed system not mentioned by the ANSI standard is the infrared scattering system. This type of system eliminates "overspill" problems at what is typically a lower cost than the radio frequency system. This option should be considered. (NOTE: The medical implications of infrared fields is not well understood; particularly the risk of delayed development of cataracts.)

Inductive loop pick-ups have been used successfully by individuals with hearing aids who wish to use pubic telephones. Older telephones had sufficient "stray" magnetic field to activate hearing aids equipped with such inductive loop facilities. Recent developments by the telephone industry resulted in more efficient telephone components that no longer leak the necessary magnetic field strength required for inductive loop pick-up (Corliss, 1981). As the telephone industry replaces the older units with new models, the ability of many hearing impaired individuals to use normal public telephone systems is being diminished. This issue deserves attention from standardization groups.

3.2.2.3 ANSI A117.1-1980, Section 4.31.5 (Telephone) Equipment for Hearing Impaired People [1190.210]

Telephones shall be equipped with a receiver that generates a magnetic field in the area of the receiver cap. If banks of public telephones are provided, then a reasonable number, but always at least one, in a building or facility shall be equipped with a volume control.

\subsubsection{ANSI A117.1-1980, Section A4.33.6, Placement of Listening Systems}

This section appears in the appendix to ANSI A117.1-1980 and as such is not part of the ANSI standard. 
A distance of 50-ft (15-m) allows a person to distinguish performers' facial expressions.

This issue has been discussed under section 3.2 .2 .1 of this document.

3.2.2.5 ANSI A117.1-1980, Section A4.33.7, Types of Listening Systems

This section appears in the appendix to ANSI Al17.1-1980 and as such is not part of the ANSI standard.

A listening system that can be used from any seat in a seating area is the most flexible way to meet this specification. Earphone jacks with variable volume controls can benefit only people who have slight hearing losses and do not help people with hearing aids. At the present time, audio loops are the most feasible type of listening system for people who use hearing aids, but people without hearing aids or those with hearing aids not equipped with inductive pickups cannot use them. Loops can be portable and moved to various locations within a room. Moreover, for little cost, they can serve a large area within a seating area. Radio frequency systems can be extremely effective and inexpensive. People without hearing aids can use them, but people with hearing aids need custom-designed equipment to use them as they are presently designed. If hearing aids have a jack to allow a by-pass of microphones, then radio frequency systems would be suitable for people with and without hearing aids. Some listening systems may be subject to interference from other equipment and feedback from hearing aids of people who are using the systems. Such interference can be controlled by careful engineering design that anticipates feedback and sources of interference in the surrounding area.

These issues were addressed under section 3.2 .2 .2 of this document with the addition of infrared scattering systems in assembly areas and the use of inductive loop pick-ups in using public telephones.

It should be noted that Martin (1977) as well as a number of other researchers (Finitzo-Helber and Tillman, 1978; Klein, 1971, Nabelek and Pickett, 1974 a,b; Plomp and Duquesnoy, 1980) have identified improvements in the acoustics of building spaces as being another "system element" by which communication with the hearing-impaired can be facilitated. This topic will be discussed further in section 3.3.3.

\subsubsection{ANSI Al17.1-1980, Section A 4.31.5 (Telephone Equipment for Hearing Impaired People}

Other aids for people with hearing impairments are telephones, teleprinters, and other telephonic devices that can be used to transmit printed messages through telephone lines to a teletype printer or television monitor. 


\subsubsection{Sound Reinforcement Systems}

As previously discussed (section 3.2 and 3.2 .2 ), sound reinforcement systems that meet the needs of hearing-impaired individuals are simply more elaborate, coverage dependent (i.e. must service a finite floor surface area occupied by an audience), speech communication systems. As a matter of practice, it should. be noted that current sound reinforcement techniques (Davis and Davis, 1976) use speech intelligibility data in their criteria. These criteria provide a reasonably objective and quantitative approach to sound system design and, in addition, are closely correlated to the users' needs. This topic will be discussed in further detail in section 3.3 .

\subsection{SUMMARY/CONCLUSIONS}

\subsubsection{Overview of ANSI A117.1-1980}

ANSI A117.1-1980 addresses only two issues of importance to the hearingimpaired: (1) relative intensity requirements of "alarm" systems with respect to background noise levels and (2) limited requirements for "assembly areas" (i.e. distance to "performers" and a listing of two audio system types used in theaters and auditoria). ANSI A117.1-1980 would be improved by a more rigorous consideration of the parameters critical to audio alerting systems and speech communication systems. In addition, appropriate emphasis should be placed upon the fact that each building requires a "system". These systems are not add-on features. Rather they require a degree of attention similar to other building systems early in the building design process. Approached from this perspective, the costs are minimized and the completed building will succeed acoustically for both hearing-impaired and unimpaired individuals.

\subsubsection{Audio Alerting Systems}

The major parameters of audio alerting systems include: (1) acoustical characteristics of the device (power spectrum, frequency response and directivity); (2) the location and spacing of acoustical devices; (3) the sound transmission properties of the building; and (4) the background noise levels in the building. Item 3 leads naturally to item 2, which, when combined with data from item 4, can be used to specify an appropriate acoustical device (item 1) for the specific needs of a given building. Though a comprehensive guide for this design process is not currently available, assistance available from professional acoustical consultants should provide satisfactory results.

Of perhaps more immediate relevance to ANSI Al17.1-1980, are performance criteria needed by the hearing-impaired and other communicatively handicapped individuals. These include specification of:

(1) sound intensity - (specified at typical listening positions) whichever of the following is greater:

(a) greater than or equal to an A-weighted sound pressure level of $65 \mathrm{~dB}$ (75 $\mathrm{dB}$ in sleeping environments) 
(b) $15 \mathrm{~dB}$ above the prevailing A-weighted equivalent sound level (24 hours)

(c) $5 \mathrm{~dB}$ above any maximum A-weighted sound level that has a duration of 30 seconds or more

(2) sound spectrum - maximum acoustical output should fall between 500 and $2000 \mathrm{~Hz}$ (alternatively between 750 and $1500 \mathrm{~Hz}$ ).

(3) temporal pattern - adoption of a temporal pattern similar to that recommended by CHABA Working Group 73 (1975).

\subsubsection{Speech Communication Systems}

As in all auditory communication systems, those designed to transmit speech intelligibly require consideration of both the source and the path to the receiver. The acoustic environment effectively modifies the acoustic character of the signal. The specific demands made upon the system (design goals) are a function of the needs of the expected receivers and their location relative to the source. Hence, the acoustic characteristics of the building space are an integral part of the system design.

Two types of speech communication systems are of relevance to the hearingimpaired; those which use electroacoustic reinforcement of the source (talker) and those which do not (person to person communication). Both of these types depend upon the "path" or acoustical environment in which communication is attempted.

\subsubsection{Statement of the Problem}

Current efforts toward the integration of hearing-impaired individuals into the "mainstream" of American society (Northcott, 1973) imposes difficulties in the area of speech intelligibility. There has been insufficient attention to architectural acoustics (i.e. the acoustical environment) in many public building spaces. All ages are affected. As stated previously, approximately 17 million people in the U.S. experience hearing difficulties that may pose problems in understanding speech. These stem primarily from class-D or distortion loss components of their hearing disability (Plomp, 1978). Further, these distortion losses cannot be compensated by mere amplification or hearing aids. Poor speech intelligibility for the hearing-impaired in public spaces is degraded further by excessive noise levels and excessive reverberation. Often, too, there is an inadequate design of the electroacoustic elements of the system (Finitzo-Heiber and Tillman, 1978; Klein, 1971; Martin, 1977; Nabelek and Pickett, 1974 a,b; Plomp and Duquesnoy, 1980).

Though the impact on communication in emergency situations is much more obvious, speech communication difficulties under non-emergency conditions can also have profound effects. Davis (1974), in a study of children's performance in school, observed that hearing-impaired youngsters enrolled in normal-hearing classes fall increasingly behind in knowledge of basic concepts when compared to their normally hearing peers. The problem of hearing-impaired children in 
understanding speech in the classroom has been identified as a possible cause of such poor performance (Finitizo-Hieber and Tillman, 1978).

Therefore, architectural acoustic design and the design of electroacoustic elements of speech/sound reinforcement systems should not neglect the requirements of the hearing-impaired if a "mainstream" philosophy is to be adhered to.

\section{3 .3 .2 Approach to Speech Communication Systems}

A comprehensive approach in designing speech communication systems, therefore, must include consideration of: (1) the receiver (speech intelligibility requirements), (2) the path (architectural acoustic requirements) and (3) the source (electroacoustic requirements).

Research applicable to these issues has proceeded from two complementary perspectives during the last decade. Acoustical engineering concerned with predicting sound reinforcement system performance for normal-hearing individuals developed techniques that combined traditional physical acoustic measurements and architectural acoustic design practices with innovative electroacoustic design procedures that have been quite successful (Peutz, 1974; Klein, 1974; Davis and Davis, 1976).

The second perspective has emphasized basic research on the speech intelligibility requirements of the hearing-impaired at such institutions as the Institute of Perception TNO (The Netherlands), Gallaudet College, and Northwestern University. This work has emphasized new quantitative techniques: (1) to assess the impact of hearing impairment upon the speech reception threshold (SRT, ) as affected by the acoustical environment (Nabelek and Pickett, 1974 a, b. Finitzo-Hieber, 1978), and (2) to characterize the acoustic environment physically, using new measurement techniques that address those aspects of the environment that are critical to speech intelligibility (Houtgast and Steeneken, 1973; Plomp and Duquesnoy, 1980; Plomp and Mimpen, 1979; Steeneken and Houtgast, 1980).

This work has laid the foundation for establishing speech intelligibility criteria that can be directly related to architectural and electroacoustic design methods. An integration of these receiver, path and source requirements is necessary to satisfy the needs of both normal and hearing-impaired building users. An overview of the current state of the above mentioned research efforts follows.

To date, the most widely used and easily understandable method of ensuring adequate speech intelligibility in rooms has been the method developed by Davis and Davis (1976), based on work initiated by Peutz (1974) and Klein (1974). This method has been used extensively by audio professionals responsible for adequate speech intelligibility in the design of sound reinforcement systems. Though the details of the method employed are beyond the scope of the current discussion, a brief statement will be given here. 
Peutz established an empirical relationship between certain physical parameters of the environment under question and the articulation loss of consonants ( $\left.A L_{\text {cons }}\right)$. $\mathrm{AL}_{\text {cons }}$ was found to be predictive of an individual's ability to understand speech in a reverberant environment (often important in large public building spaces). Specifically, Peutz derived the following relationship:

$$
\text { \% } \begin{aligned}
\text { AL } & =\frac{200 D^{2} \mathrm{~T}^{2}}{\mathrm{VQ}} \\
\text { where: } \mathrm{D} & =\text { distance from the listener to the source (m) } \\
\mathrm{T} & =\text { the reverberation time of the space (sec) } \\
\mathrm{V} & =\text { volume of the space }\left(\mathrm{m}^{3}\right) \\
\mathrm{Q} & =\text { directivity factor of the source }
\end{aligned}
$$

The acoustical engineer controls the reverberation time ( $T$ ) by proper design of the architectural acoustic elements of the building space (specifically their absorption characteristics). The engineer can also specify electroacoustic devices (when used) that meet particular directivity requirements. (Note: A serious impediment, however, is the inadequacy of technical data on commercially available electroacoustic transducers).

As a "practical working 1imit" for sound reinforcement systems, an $\mathrm{AL}_{\text {cons }}$ of $\leq 15$ percent has been established for normal hearing individuals (Davis and Davis, 1976). This empirically established criterion is used in combination with the requirement that the signal-to-noise ratio be a minimum of $25 \mathrm{~dB}$.

Though data do not exist for establishing a limit on $\mathrm{AL}_{\text {cons }}$ for the hearingimpaired, many speech communication systems currently in use would not meet the above limit. Therefore, adoption of the above limit in combination with signal-to-noise requirements could be used to greatly improve speech intelligibility generally, and for the hearing-impaired particularly.

Specific approaches to speech intelligibility requirements with regard to the hearing-impaired has been undertaken, as mentioned, by researchers affiliated with the Institute of Perception in the Netherlands. Houtgast and Steeneken (1973) developed a new physical acoustic measurement technique for characterizing room acoustics called the modulation transfer function (MTF). The MTF of a space when converted mathematically to a speech transmission index (STI) was found to correlate well with observed speech intelligibility (speech reception threshold, SRT) observed in that space (Duquesnoy and Plomp, 1980; Houtgard, et al., 1980; Plomp, et al., 1980). The results of this research effort initiated a data base on acoustic criteria to serve the hearing impaired (Duquesnoy and Plomp, 1980; Plomp and Duquesnoy, 1981). Though current efforts toward using the MTF technique directly are at the research level, data have become available suggesting that the reverberation time ( $T$ ) acceptable for normal-hearing listeners must be reduced to provide acceptable communication for hearing-impaired individuals and must be related to the degree of distortion loss (class-D) experienced $\left(\mathrm{T}_{\max }=0.75^{\mathrm{D}} \mathrm{T}\right.$, where $\mathrm{D}$ is the distortion loss expressed in $d B$ ). 
Fundamental research continues on the relation between the MTF technique and speech intelligibility requirements. The development of state-of-the-art measurement instrumentation and methodologies to characterize rooms acoustically is the next step toward the application of insights derived from the emerging data,

Research at the National Bureau of Standards is currently directed toward physical acoustic room characterization. One aspect of this effort includes (a) the development of an absolute sound power source (Cook, 197) and (b) the development of a modulated reverberation (MR) technique to improve upon traditional decay curve reverberation time measurements. At this time the research is focusing on a methodology for the accurate determination of sound absorption coefficients of acoustical building materials. This involves the measurement of phase angle changes imparted by a room on the infrasonic modulation (below $20 \mathrm{~Hz}$ ) of the source output. The modulation transfer function (MTF) technique used to predict speech intelligibility in a room could be developed as an extension of the same system. The MTF is derived by observing amplitude changes imparted by a room on such an infrasonically modulated signal.

\subsubsection{Economic Considerations}

The cost of improving communication systems in buildings in general, and to accommodate the needs of handicapped individuals in particular, must be controlled. Recently, a method has been developed at the National Bureau of Standards (Weber and Rudder, 1981) for estimating the costs of alternative ways of achieving target levels of sound isolation (both outdoor-to-indoor and between building spaces). Though the acoustical techniques employed for sound isolation differ from those used to control reverberation time within building spaces, the same economic model (or cost analysis method) is applicable to the latter as well.

Further development of the cost-benefit analysis technique for application to the selection and use of sound absorptive building materials would be very useful. Though system designs employing appropriate electroacoustic and architectural acoustic elements are not expected to be prohibitive due to costs, a quantitative method for predicting those costs and for making decisions among alternative designs is essential in meeting auditory communication requirements for the hearing-impaired.

\subsection{FURTHER RESEARCH}

Additional research is needed in nearly all areas addressed thus far. At present, none of the issues has been resolved adequately. However, there are several areas in which simple experiments would prove very effective.

(1) A comprehensive approach to audible alarm systems is needed. Psychoacoustic data on what constitutes an adequate acoustic "alarm" for all building users including the hearing-impaired are particularly needed. Design techniques that will assure delivery of that acoustic signal to building occupants must then be worked out based upon these data. 
(2) Speech intelligibility requirements for hearing impaired bullding users must be integrated into a single set of criteria and design methods that can be used to achieve adequate speech communication systems.

(3) Practical physical acoustic measurement instrumentation must be developed. Methodologies for characterizing the acoustic environment of building spaces (e.g. MTF and MR) in ways that are meaningful to the building design process must be worked out.

The impact of such research is not limited to the approximately 17 million individuals experiencing communication difficulties due to hearing losses. Everyone who uses public buildings is affected by the quality of the communication capabilities achieved. 
Tactile communication systems are used in buildings to provide both directional and hazard warning information primarily to visually handicapped individuals. These systems typically rely upon raised letters, surface markings, and marked doorknobs to communicate relatively brief bits of information to visually handicapped individuals. Information systems, for example, which provide directional and locational information within a building, are intended to guide a person. Hazard warning systems on the other hand, are intended to stop or slow down a person before the hazard is encountered. Thus, intersections, elevators, stairs, excavations and the like must be marked with a clearly identifiable warning message to prevent accidents.

Typically, directional and general information sytems are designed to be sensed by the fingers or hand. They are located on vertical surfaces of ten at about eye leve1, although there are no consistent requirements for location. These systems use alphanumeric or Braille characters to convey information, although one researcher, Genensky (1980), has proposed the use of shapes for encoding "men's" and "women's" restrooms.

Hazard warning systems are usually located on horizontal surfaces and are designed to be sensed with the feet or a cane. An exception is a knurled or roughened doorknob used to indicate the door to a hazardous area and which is sensed by the hand and fingers. The hazard warning, typically not specific in content, indicates the presence of a hazard but gives no additional information about the nature of the hazard.

An area of tactile communication which has recelved little code attention is that of providing emergency information such as fire egress. No provisions currently exist for indicating fire exits, routes, and safe havens with any sort of tactile code. Yet, because of smoke layering and obscuration during building fires, all building users can become visually handicapped during a fire. Emergency tactile guidance systems thus have the potential for providing essential egress information to all users.

\subsection{CODE REQUIREMENTS}

Both the ANSI Al17.1 Standard and the ATBCB rule address requirements for tactile communication. These are presented in table 3 and figure 1 which present the requirements in each area for each code. These requirements cover the areas of information signage and tactile warnings. Emergency egress information is not addressed. Table 4 also includes similar information from a variety of state codes. 
Table 2. Code Requirements for Tactile Warnings

ATBCB

ANSI A117.1 - 1980

ELIMINATED

\subsection{Tactile Warnings}

4.29.1 General. If tactile warnings are required, they shall comply with 4.29 .

4.29.2* Tactile Warnings on Walking Surfaces. Tactile warning textures on walking surfaces shall consist of exposed aggregate concrete, rubber, or plastic cushioned surfaces, raised strips, or grooves. Textures shall contrast with that of the surrounding surface. Raised strips or grooves shall comply with

Fig. 40. Grooves may be used indoors only.

4.29.4 Tactile Warnings at Stairs. Al1 stairs, except those in dwelling units, in enclosed stair towers, or set to the side of the path of travel, shall have a tactile warning at the top of stair runs (see Fig. 41).

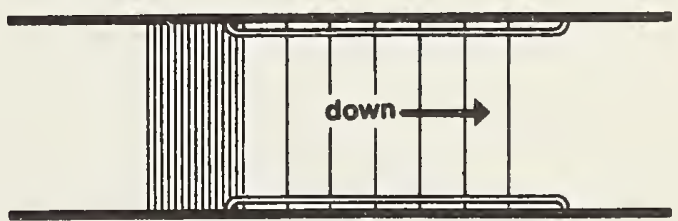

Fig. 41

Tactile Warning at Stairs

4.29.5* Tactile Warnings at Hazardous Vehicular Areas. If a walk crosses or adjoins a frequently used vehicular way, and if there are no curbs, railings, or other elements detectable by a person who has a severe visual impairment separating the pedestrian and vehicular areas, then the boundary between the areas shall be defined by a continuous 36-in (915-mm) wide tactile warning texture complying with 4.29.2 (see Fig. 42). 
4.29.6* Tactile Warnings at Reflecting Pools. The edges of reflecting pools shall be protected by railings, walls, curbs, or tactile warnings complying with 4.29 .2 .

4.29.7* Standardization. Textured surfaces for tactile warnings shall be standard within a building, facility, site, or complex of buildings.

\section{A4.29 Tactile Warnings}

A4.29.2 Tactile Warnings on Walking Surfaces. Warnings set slightly more than one pace (24 in to 48 in $(610 \mathrm{~mm}$ to $1220 \mathrm{~mm}$ )) in front of a hazard allow a blind person to perceive the signal, follow through with one last step, and stop before encountering the hazard. People who use long canes will usually detect a textured surface with their cane before they detect it with their feet.

A4.29.3 Tactile Warnings on Doors to Hazardous Areas. Tactile signals for hand reception are useful if it is certain that the signals will be touched.

A4.29.5 Tactile Warnings at Hazardous Vehicular Areas. Curbs on sidewalks serve as customary tactile cues for the edge of a street. The abrupt change in level is easily perceived by cane or foot.

A4.29.6 Tactile Warnings at Reflecting Pools. Other hazards besides reflecting pools may require similar protection.

A4.29.7 Standardization. Too many tactile warnings or lack of standardizatin. weakens their usefulness. Tactile signals can also be visual signals to guide dogs, since dogs can be trained to respond to a large variety of visual cues. 
Figure 1. ANSI A117.1 (1980) Diagram of tactile warning at hazardous vehicular areas

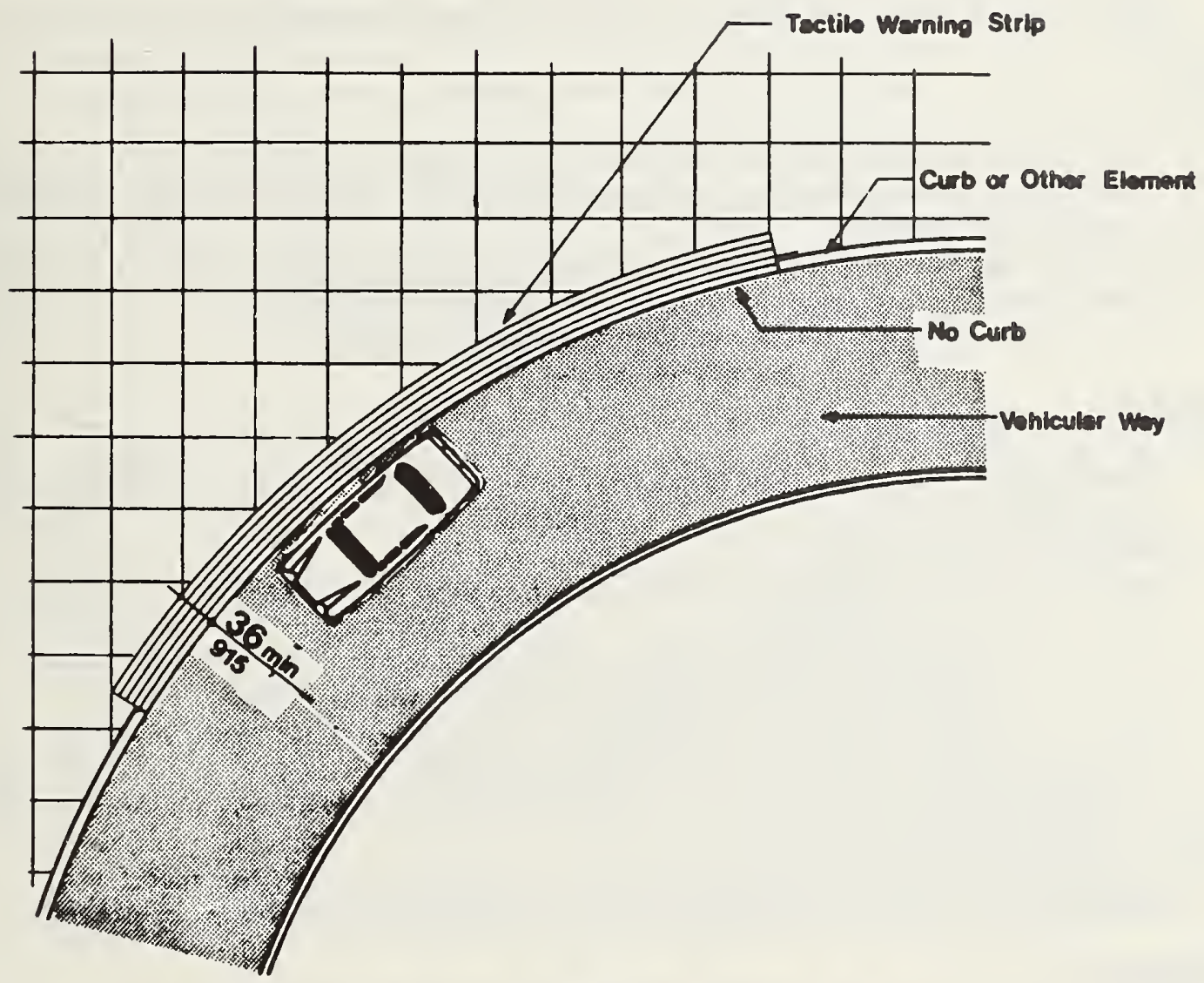

Fig. 42

Tactile Warning at Hazardous Vehicular Areas 


\section{GSA}

- use short staccato cue, such as several rows of brick across sidewalk

to cue danger (such a stair, direction change etc.) perpendicular to

line of movement -- cue should be rougher than surrounding texture

- use design, planting and paving to indicate direction of access,

changes in level and slope, intersection and adjacent areas/facili-

ties

- narrow strips of texture -- $4^{\prime}-18^{\prime \prime}$ width = danger

- wide strip - $36^{\prime \prime}$ minimum to signal adjacent areas and facilities

DOD

- provide textured warning strips (e.g. paint-on gritted epoxy) on walk or floor perpendicular to head of stairs, ramps (except curbside) and other hazards

- strips should be $1 / 16 "$ high, $3 "$ wide with 3 " intervening spaces and $36 "$ long -- in contrasting color (safety yellow)

- use strips of vinyl or rubber in carpeted areas

Illinois

- provide tactile warning signals of consistent texture within building or site

- use only as an alert

- pattern -- (a) applied strips forming grooves $1 / 8$ " deep and bonded to surface

(b) continuous sheet with grooves $1 / 16$ " minimum depth

(c) grooves $1 / 8$ " deep integral to walking surface

(d) change of material to one with $1 / 8^{\prime \prime}$ deep grooves

- width of signal shall be $2^{\prime} 0$ " perpendicular to grooves if there is a perceivable difference in hardness between walkway and signal and $3^{\prime} 0$ ' if no difference

- 4" wide guidestrips are effective

- use cue to indicate hazardous area along with or pedestrian area

\section{Minnesota}

- use differences in surface texture to identify ramps and curb cuts

- use tactile floor strips to identify abrupt changes in floor elevation

$\underline{\text { Texas }}$

- use special rough or textured surfaces to signal approaching ramps, walks intersections

- use curbs to indicate approaching vehicular crossing

\section{Washington}

- use tactile cues, textural change of surface, to provide continuity of directional information, and serve as warning against hazards

- floors at head of open stairs, ramps, curbs should have abrasive strips or textured flooring material 


\subsection{TACTILE WARNINGS ON HORIZONTAL SURFACES}

Only limited research has been conducted on the perceptability of tactile warning strips in public places. These strips designed to be felt by a foot or a cane, provide warning of a possibly hazardous transition in the walking surface. Thus, such strips would be located at the head of stairs, at curbside before a street crossing, at platforms in transit stations, and at similar abrupt changes in horizontal movement planes.

Assessing the effectiveness of such strips is a difficult task, for unlike most tactile (psychophysical) research, the users are wearing shoes which reduce their tactile sensitivity to an unknown and variable degree. If the user is relying upon a cane, he/she still does not experience direct tactile contact with the strip. As a result, specification of the adequate stimulus for tactile warning becomes much more complex than simply knowing the sensitivity of the soles of the feet. Such specification can best be determined behaviorally by assessing the area, surface characteristics, and extent of surface change of the strip that a significant number of visually impaired persons wearing specified or known foot gear can detect reliably.

Aiello and Steinfeld (1979) conducted a three phase study designed to determine some of the problems that the visually impaired face during movement through an unfamiliar set of buildings. In the first phase, 28 visually handicapped people walked a specified route using recorded directions in a university building which required the use of a variety of orientation cues. Observers differed in their degree of visual handicap, with at least half being partially sighted with some degree of color, light, and/or object perception. As a result, the variations in color contrast were studied along with the tactile variables. A set of recorded directions were given to participants at the beginning of each of five segments of a specific route. An observer noted all directional and environmental problems and recorded the time to complete the walk. The participants, who required an average of seven minutes for the walk, completed both a map and a questionnaire at its end. They noted three major problems: disorientation and confusion due to large areas and irregular paths, hazardous and difficult negotiation due to obstacles, and poor directions.

Phase two, which used eight participants from phase 1 in a laboratory project, was designed to explore variables in the design of tactile warning signals Walking performance parameters such as pace gait (feet/minute) and stopping distance (after a tactile signal was felt) were assessed to determine baseline performance. Next, the minimum raise (height) detectable by either cane or feet was determined. Finally, parameters related to configuration such as abrasive strips, abrasive areas, small area ribbed rubber mats and large area ribbed rubber mats were assessed. Raise varied from 1/64-1/8 inches. Observers noted cane technique, sensing method (feet or cane), and signals detected. Preference data were also obtained. Participants strongly preferred the larger area rubber matting because of its greater area, texture, resiliancy, and distinctive sound characteristics. Review of the results from the eight subjects suggested that raise height should be no more than $1 / 8$ inch but should be at least $1 / 16$ inch. Heights greater than $1 / 3$ inch may become tripping hazards (although such heights were not examined in the present experiment). 
Larger areas seemed to be preferred particularly if patterned or roughly textured. Signals which contrasted in resiliance (and color) with surrounding floor surfaces also appeared to be more effective. The critical issue was depth, or the distance between the tactile cue and the signaled hazard, for which these authors recommended 18-36 inches, partly because the average stopping distance (after detection of a tactile cue) was 2.82 feet with a range of 1.1 to 4.0 feet. Observation also indicated that the diagonal cane technique yielded much shorter stopping distances. The authors recommended that signal placement be removed by an intervening area from the staircase hazards. This area should, however, be colored the same as the hazard to focus attention on the hazard and not on the signal.

Only four types of tactile surfaces were assessed in this experiment--masking tape layers, abrasive strips, areas of an unspecified material, and ribbed rubber mats (with ribs perpendicular to the line of travel). Footgear of the participants was not recorded. Tactile cues were tested only for level surfaces--no staircases were involved. Use of visual cues was not examined separately for the partially sighted participants. Only three levels of raise were assessed, 1/64, 1/32, $1 / 8$ inches. Measurements of floor resiliance were not taken nor was the patterning of the resiliant material specified or varied. Subjects were familiarized with signals before the experiment began and told the general type of configuration to expect for each experimental session.

In phase three the recommended tactile warnings were tested in an actual building using five of the participants from phase two. These tactile warnings were installed at the tops of all staircases and before elevators on two floors. Raised numerals were also provided on an elevator control panel. Participants were familiarized with both the tactile warnings and the numerals. Reliance upon the warnings and performance with the numerals were observed and recorded. Participants again provided maps of the route they followed at the conclusion of testing. Distance of the tactile cue for the staircases was varied from 18-36". Again an intervening area was left between the cue and the first step. Results indicated that an 18 inch "signal" was acceptable in most cases except where a staircase was approached straight on. Here a 24 inch "signal" would have been more acceptable. (Performance measures were not indicated, however.)

From the assessment of directional indicators, the authors reported that subjects found the raised numerals on vertical surfaces very difficult to use--perhaps because they had not been trained in the use of arabic characters. Even so, those participants who did use the numerals found them difficult to read. With practice, their performance improved but they reported that although the numeral height of $1 / 2$ inch was acceptable, the stroke width of $1 / 16$ inch was too thick. As a result the authors recommended a sharper numeral with a greater stroke width to height ratio.

Based upon the data obtained in this study, Aiello and Steinfeld (1979) recommended tactile warning strips for stairs in a path of travel, at passenger loading platforms, and at the intersection of pedestrian and vehicular circulation paths. These strips should take the form of $1 / 8$ inch grooves running parallel to the hazard edge with a minimum width of 24 inches if there is a 
change in perceived hardness and 36 inches if there is not. They also recommended the use of continuous handrails on staircases with extension of one inch at the top and the bottom. Other recommendations included the use of tactile signals--roughened surfaces--on door openers for doors to hazardous areas; as well as the use of raised characters $1 / 32$ inches from the surface an at least $5 / 8$ inches high or indented characters $1 / 32$ inches deep with a strokewidth of a least $3 / 8$ inches. The authors provided no data to support their recommendations for handrails or door tactile warnings. They did not discuss the composition of door tactile warnings either.

Templer (1980) also conducted a study of tactile surfaces for visually impaired pedestrians. He noted (page 44-45) that "while various types of tactile guides have been used to aid visually handicapped pedestrians.. . there appears to have been no attempt to determine experimentally what types of outdoor surfaces textures are most easily detected by the visually impaired." Templer's study was designed to assess the response to a variety of materials and surfaces that could be added to existing pedestrian pathways.

Templer (1980) selected eleven textured surfaces and a twelfth control surface (normal sidewalk) for study. Each surface was four feet wide and six feet long except for one 15 foot long section. The textures varied from thermoplastic solids, to ruled concrete, exposed aggregate, asphalt, paving brick, and similar material. Characteristics of each surface are reported by Templer (1980) in detail. A total of 52 subjects were used, 31 of which were visually handicapped and legally blind. The remaining 21 subjects were physically, but not visually handicapped. Visually handicapped subjects included those with low partial vision, high partial vision, and total blindness. See Templer (1980) for a discussion of criteria for determining extent of visual handicap.

Subjects were initially familiarized with all surface textures. Then, subjects were asked to detect the surfaces one at a time in random order. Their task was to walk forward from a starting point which was randomly varied from 15 to 22 feet from the textured surface, and to stop immediately upon detecting any change in the surface. Guide ropes were placed at both sides of the test area. Distance traveled along the textured surface was recorded along with the time to traverse the last 10 feet of the approach path. If a surface change were detected, subjects were asked to rate the ease of detection on a four-point rating scale. The textured surfaces were also evaluated in terms of comfort, balance and stability for non-visually but physically handicapped persons, again using a rating scale.

The results indicated that those subjects with high partial vision detected 85 percent of the test materials. Of the people with low partial vision, 86 percent successfully detected seven of the twelve materials, while 70 percent detected another three materials. For the totally blind subjects, 86 percent detected five of the twelve materials while 70 percent detected three additional materials. Only three materials, thermoplastic strips, exposed aggregate, and pliant polymer, were detected by more than 85 percent of all visually handicapped subjects. Two of these materials, thermoplastic strips and exposed aggregate, were also rated as easily detectable by all subjects. Measurement of stopping distances, recorded for all subjects, indicated that totally blind 
subjects took longer than those with low partial vision who took longer than those with high partial vision. All seven materials tested were detected by 90 percent of the totally blind subjects within 48 inches of the start point, and one, pliant polymer, within 30 inches. Stopping distances ranged from $0-24$ inches for low and high partial by sighted subjects. Comfort ratings of the surfaces by other handicapped subjects revealed that the exposed aggregate surface was rated as moderately or greatly adverse. All of the other materials received mean ratings in the categories of "not at all" or "a little" effect on comfort, balance, and stability.

Inclusion of users with non-visual handicaps is a very important consideration in developing recommendations for tactile surface warnings. Such warnings may impede movement by the wheelchair bound, crutch, cane or walker users, and cause tripping hazards for all people.

Templer (1980) commented that most visually impaired subjects were able to detect changes in surface materials studied with little difficulty. Exact specifications of the physical characteristics of the most effective set of warning materials still remains, however. For those materials tested, a 30 inch to 48 inch strip of material was needed for detection. Thermoplastic strips six inches wide and spaced at six inch intervals across the direction of movement were found to be both detectable and comfortable. These patterns are very different from the ANSI recommendation of $3 / 4-2$ " strips separated by $1 / 4$ " = $3 / 4^{\prime \prime}$.

The work by Templer and Aiello and Steinfeld represents a preliminary investigation of the characteristics of tactile surfaces that could be used for movement guidance and direction finding. Use of both behavioral and preference techniques appears to be a viable means for assessing tactile effectiveness.

Nevertheless, numerous questions remain to be answered in the field of tactile warnings. From a research point of view, the number and kind of subjects studied should be expanded and defined. Visual capacity should be defined consistently throughout all research addressed to tactile warnings and communication systems. Age, sex, movement experience, education and similar demographic variables must be documented and studied. Similarly, tactile deficits if any should be noted. Use of a cane should be documented along with kind of footgear worn. Footgear in fact is never mentioned in either study reviewed in this section; yet it might adversely or differentially affect sensitivity. Finally, the characteristics of the tactile stimulus should be explored and specified in terms of material, resiliancy, raise, patterning, slip resistance, and contrast with surrounding materials. Furthermore, the optimum physical dimensions and application pattern remain to be explored in greater detail. For example, Aiello and Steinfeld (1979) recommended depths of 18 to 36 inches while Templer (1980) found depths of 48 inches to be most appropriate for totally blind subjects. Such discrepancies must be further assessed. 


\subsection{DIRECTIONAL AND INFORMATIONAL CUES}

Both the ANSI Al17.1 Standard and the ATBCB Rule treat two types of tactile signage for manual communicating; raised or incised alphanumeric characters and textured surfaces on door knobs to hazardous areas. Details of the alphanumeric characters are specified in terms of height $(5 / 8-2$ ") width ( $1 / 4$ "minimum) and depth $\left(1 / 32^{\prime \prime}\right)$. See tables 5 and 6 . Details of the textured warning are less specific. These warnings may be achieved by knurling, roughening, or applying materials to the hand contact surface. The issues of consistency in materials and most effective tactile cues are not addressed by either standard. 
Table 5. Code Requirements for Tactile Communication

\begin{tabular}{|c|c|}
\hline $\begin{array}{cc}\text { ATBCB } & \text { Rule } \\
1190.200 & \text { Signage }\end{array}$ & $\begin{array}{l}\text { ANSI A117.1-1980 } \\
4.30-\text { Signage }\end{array}$ \\
\hline $\begin{array}{l}\text { (c) Raised or incised characters. } \\
\text { Provide numbers and letters that } \\
\text { are: } \\
\text { ( } 1 \text { ) Raised or incised from the } \\
\text { background surface } 1 / 32 \text { inch } \\
\text { ( } 0.8 \mathrm{~mm} \text { ). Also incise or raise } \\
\text { symbols and pictographs in this } \\
\text { manner. } \\
\text { ( } 2 \text { ) Between } 5 / 8 \text { inch ( } 16 \mathrm{~mm} \text { ) } \\
\text { and } 2 \text { inches ( } 50 \mathrm{~mm} \text { ) high. } \\
\text { (3) Sans serif with sharply } \\
\text { defined edges. } \\
\text { ( } 4 \text { ) If incised, provided with } \\
\text { at least a } 1 / 4 \text { inch ( } 6 \mathrm{~mm} \text { ) stroke } \\
\text { width. }\end{array}$ & $\begin{array}{l}\text { 4.30 Signage } \\
4.30 .1^{*} \text { General. All signage that } \\
\text { provides emergency information or } \\
\text { general circulation directions or } \\
\text { identifies rooms and spaces shall } \\
\text { comply with } 4.30 .2,4.30 .3 \text {, and } \\
4.30 .5 \text {. Tactile signage shall also } \\
\text { comply with } 4.30 .4 \text {. } \\
4.30 .2 * \text { Character Proportion. } \\
\text { Letters and numbers on signs shall } \\
\text { have a width-to-height ratio between } \\
3: 5 \text { and } 1: 1 \text { and a stroke-width-to- } \\
\text { height ratio between } 1: 5 \text { and } 1: 10 \text {. } \\
4.30 .3 * \text { Color Contrast. Charac- } \\
\text { ters and symbols shall contrast with } \\
\text { their background - either light } \\
\text { characters on a dark background or } \\
\text { dark characters on a } 1 \text { ight back- } \\
\text { ground. } \\
4.30 .4 * \text { Raised or Indented } \\
\text { Characters or Symbols. Letters and } \\
\text { numbers on signs shall be raised or } \\
\text { incised } 1 / 32 \text { in (0.8 mm) minimum and } \\
\text { shall be sans serif characters. } \\
\text { Raised characters or symbols shall be } \\
\text { at least } 5 / 8 \text { in ( } 16 \text { mm) high but no } \\
\text { higher than } 2 \text { in ( } 50 \text { mm). Indented } \\
\text { characters or symbols shall have a } \\
\text { stroke width of at least } 1 / 4 \text { in } \\
\text { (6 mm). Symbols or pictographs on } \\
\text { signs shall be raised or indented } \\
1 / 32 \text { in ( } 0.8 \text { mm) minimum. }\end{array}$ \\
\hline
\end{tabular}


Table 6. Tactile Communication Requirements from Other Codes

Post Office

- raised/incised letters and numerals required for access

- room or office identification shall be mounted $4^{\prime}+6^{\prime \prime}$ above finished floor and adjacent to entryway consistently on left or right side of door

- incised letters 1" high, 1/32" deep (minimum)

- raised letters 5/8" high, 1/64" raised (minimum)

HEW

- raised letters/numerals to identify rooms/offices

- placed on corridor wall on latch side of doorway approximately 60" from floor

- characters 5/8" high, 1/32" raise (minimum)

- door indentification -- 60" centerline preferred (54-66" range)

\section{Illinois}

- tactile signage required using raised characters

- raised 1/32", height $21 / 2 "$ (minimum

- mounted $4^{\prime}-6^{\prime \prime}-5^{\prime}-0^{\prime \prime}$ above surface

- mounted at latch side of door

Massachusetts

- egress signage, raised or recessed - 1/4" minimum height

- braille may supplement, but not substitute

Minnesota

- tactile identification required -- raised or recessed.

- mounted on wall adjacent to the door on latch sides between 4 '6"

$(1.372 \mathrm{~m})$ and $5^{\prime} 6^{\prime \prime}(1.676 \mathrm{~m})$

- 5/8"-1" (16-25 mm) letters and 2-3" (51-76 mm) numerals raised 1/32"

or recessed $1 / 8$ " in roman or arabic type

$\underline{\mathrm{UBC}}$

raised or recessed letters mounted between $4^{\prime} 6^{\prime \prime}$ and $5^{\prime} 6^{\prime \prime}$ on wall adjacent door handle 


\section{New Hampshire}

- signs, numbers/graphics for egress should be permanently raised 1/8" (3 $\mathrm{mm}$ ) with $11 / 4^{\prime \prime}$ (32 $\mathrm{mm}$ ) minimum height

- braille may supplement but not substitute

\section{New Jersey}

- $\quad$ ign identification shall have raised symbols $3 / 4^{\prime \prime}$ high mounted 4 $4^{\prime \prime}$ above finished floor on wall nearest door handle when door is closed - routes of travel shall be similarly marked

\section{North Carolina}

- signs for identification shall have raised or notched letters/numbers mounted 4'6" - 5'6" from floor on side nearest door handle when door is closed.

Ohio

- raised or incised letters

- raised letters recommended when letter heights between $1 / 2$ " (15 mm)

(minimum) and $1 "(25 \mathrm{~mm})$-- larger letters may be raised or incised. - preferred projection from sign face is $1 / 64^{\prime}(0.4 \mathrm{~mm})$

- room or office identification should be mounted at a height of between

$54^{\prime \prime}(1370 \mathrm{~mm})$ and 66" (1675 mm) above floor

- Braille may supplement

\section{Texas}

- raised or incised letters/numbers should be used for identification and should be placed to left or right of doorway, on handle side, about 5' above floor level

$\underline{\text { Utah }}$

- use raised/incised letters or numerals mounted 4'-6" to 5'-6" above floor, on side nearest door handle when closed

\section{Washington}

- use tactile signs with raised or grooved lettering $1 / 16^{\prime \prime}$ with height not less than 1 " or greater than 2 "

- do not mount more than 66" above floor, adjacent to strike jamb

- use to identify openings to public spaces, stairs, loading platforms, stages, mechanical equipment rooms, fire escapes, elevators, hazardous areas 


\subsubsection{Skin Sensitivity}

The first question to be resolved in a consideration of tactile communication is that of overall skin sensitivity to discrete tactile stimuli.

The sensitivity of the skin has been investigated by studying spatial

responsiveness using methods such as point localization and two point thresholds and by determining direct pressure sensitivity. In point localization, subjects point to or touch a spot or point on the skin previously touched by the experimenter (Stevens and Green, 1978). The error of localization between the two points is measured. Errors in point localization vary from $1.5 \mathrm{~mm}$ on the index fingers to $9.5 \mathrm{~mm}$ on the back (Kenshalo, 1978). There is a proximodistant gradient (extremity to trunk) of decreasing errors of localization for both the upper and lower extremities, with the most sensitive areas being the fingers, face and hallux (big toe) (Weinstein, 1968). Males and females are about equally sensitive as measured by point localization, although males are slightly more sensitive for palm measurements (Weinstein, 1968).

The two point threshold or "limen" is defined as the smallest separation of two blunted points presented simultaneously that can be recognized as two distinct spatially separated touch stimuli (Kenshalo, 1978). Two point threshold measurements are typically four times as large as measures derived from point localization data (Kenshalo, 1978), even though the procedures used to measure the two differ only in that localization stimuli are presented successively while two point stimuli are presented simultaneously. The pattern of response to two point stimuli is very similar to that for point localization. Essentially, the extremities such as the fingers are most sensitive and areas of the trunk are least sensitive with a range of value from about $2.5 \mathrm{~mm}$ for mid-finger to $47.0 \mathrm{~mm}$ for the calf (for two-point limen measures) and about $1.4 \mathrm{~mm}$ for the index finger to $12.5 \mathrm{~mm}$ for the back for point localization measures (Kenshalo, 1978).

Touch sensitivity varies for different body regions according to the method selected to study sensitivity. While the pattern of response is similar for two-point and point localization measures, despite the greater sensitivity to the point localzation, the pattern for pressure sensitivity varies from $.5 \mathrm{mg}$ on the nose, $11.4 \mathrm{mg}$ on the index finger to $36.7 \mathrm{mg}$ on the hallux and $40.3 \mathrm{mg}$ on the calf (Kenshalo, 1978). Weinstein (1968) who correlated threshold data from the three measures of tactile sensitivity, pointed out that there were low non-significant correlations between point localization/two point measure and pressure measures but a high (.92) correlation between the two spatial measures. Thus, the index finger ranked first for point localization but fifteenth for pressure sensitivity.

For punctate stimuli (passive touch), Kenshalo (1978) reported that the absolute threshold varies from $0.26 \mathrm{erg}$ on the ball of the thumb to 0.36 to $1.090 \mathrm{erg}$ for the other fingers. Females tend to be slightly more sensitive than males for pressure sensitivity (Weinstein, 1968).

Schiff (1980) commented that measures of tactile sensitivity correlate only moderately with each other even in the same area of skin. He claimed (p. 19) 
that "Tactual judgments are apparently based on complex phenomena and no single measure of skin sensitivity is a particularly useful index of any other." Yet since spatial sensitivity is probably more critical than pressure sensitivity for tactile communication, it is important to know that both the finger and halux are most sensitive to measures of object distance.

\subsubsection{Visual Impairments and Tactile Sensitivity}

The data discussed up to this point have been obtained primarily with healthy, young adults. There is some evidence that visually impaired observers differ much more widely in their sensitivity to touch.

For example, Linkblom and Lindstrom (1976) measured thresholds for passive touch in both normal and blind subjects. Using 32 subjects, 10 of whom were blind, they administered short mechanical pulses of about $100 \mathrm{~Hz}$ to the finger pads and varied the skin indentation amplitude of the stimulus pulse.

They recorded the lowest amplitude that subjects reported feeling on 3 to 4 consecutive stimulations. Inspection of the data revealed that thresholds were generally about 30 percent lower with less variation for blind subjects than for normal subjects, suggesting that the blind may have somewhat greater sensitivity. The greater sensitivity may be due to differences in manual labor, or to the generally younger age of the blind subjects. The authors also found no difference between fingers, even for those used for reading braille or for handedness or sex for blind subjects, but did find slightly lower thresholds on the dominant side for the non-blind subjects.

Heinrichs and Moorhouse (1969) measured tactile thresholds in healthy seeing subjects, blind, and blind diabetic subjects. Three threshold measures were obtained; vibratory-perception, light-touch perception, and two-point perception. Although clinical measures do not often demonstrate diabetic loss of sensitivity (neuropathy) in the hands, the tactile measurements obtained for the ten diabetic subjects indicated that all perceptual threshold measurements were higher than for the non-diabetic subjects with no overlap in the threshold range for the pressure and two-point measurements. Thus, the two-point measures for the non-diabetic subjects varied from 1.3 to $1.9 \mathrm{~mm}$ while for the diabetic subjects they varied from 2.3 to $2.0 \mathrm{~mm}$. In addition only two of the ten subjects indicated any awareness of sensory loss in their fingers. The authors indicated that: "The present study arose from the observation that diabetic blind persons have difficulty in reading Braille. The findings appear to explain this fact. Subjects with marked elevation of touch-perception thresholds in their fingertips were scarcely able to feel the type at all. In others the difficulty was probably caused by their inability to perceive clearly the individual points. In particular, the threshold for two-point discrimination ranged from 1.3 to $1.0 \mathrm{~mm}$ in the non-diabetic and from 2.3 to $2.9 \mathrm{~mm}$ in the diabetic blind subjects. The standard distance between the points in English Braille type is $2.2 \mathrm{~mm} "$ (Heinrichs and Moorhouse, 1969, p. 74-75).

These findings suggest strongly that spatial separation of communication elements for the blind should exceed $3.0 \mathrm{~mm}$. What is not known, however, is the general sensitivity for tactile stimuli of the population of diabetic blind 
subjects. The ten subjects studied by Heinrichs and Moorhouse were in reasonably good health with medical control of the diabetic symptoms at the time of the test. These subjects were also young, with a mean age of 31 . As a result, the threshold measures might be higher for aged or more severely ill patients, with consequently serious implications for tactile communication systems.

In the U.S. the number of diabetic blind patients is about 5 percent of the adult legally blind population (Westet, 1976). Furthermore, 46,000 newly diagnosed cases of eye problems due to diabetes are reported each year, with 90 percent of these cases involving people over 45 and 40 percent over age 65 (Westet, 1976).

\subsubsection{Braille Sensitivity}

The data discussed on tactile perception thus far relate primarily to passive perception in which stimuli are applied to the subjects' skin. The subject typically remains motionless during stimulation. Yet, touch in the real world is active; the observer moves his hand across objects, setting up much more complex patterns of stimulation. Kenshalo (1978, p. 48) comments, "But touch, as experienced in daily life, should be considered as an exploratory rather than as merely a receptive sense. What little quantitative data exist indicate that the skin exhibits far greater acuities when used in active exploration than when used as a passive receptor."

Kenshalo (1978) discussed Braille reading as a task that depends heavily on active tactile spatial acuity. He commented that the six embossed Braille dots for a character stand $1 \mathrm{~mm}$ above the surface with each dot separated from its neighbor by $2.3 \mathrm{~mm}$. Legibility for Braille is only moderately reduced when this space is reduced to $1.9 \mathrm{~mm}$. (Obviously, these data were not derived from diabetic blind subjects.) If subjects are not allowed to move their fingers or make rapid scanning movements, the ability to read Braille is just about eliminated. Kenshalo (1978) noted further that observers can detect a $1 \mathrm{~mm}$ groove in an otherwise smooth surface, if allowed to move their hands. Similarly, Lederman and Taylor (1972) and Lederman (1974) reported that the perceived roughness of a surface is related not only to its physical characteristics such as groove width, but also to the amount of force applied by the finger. Heimar (1973, p. 67) commented that "The ability of the fingertips to sense textures and surface details reflects the skin's capacity to detect patterns which are shifted over its surface (i.e., spatiotemporal cutaneous patterns)." Furthermore, Schiff (1980) commented that the manipulative skill of the observer can be critical in enabling him to make fine discriminations.

Lappin and Foulke (1973) investigated some of the parameters which might be manipulated to increase Braille reading speed. Braille is typically read at about 60/80 wpm while English print is read at 200-400 wpm with 1000 wpm occasionally reported for speed readers. Braille readers generally use one finger, the index finger, to read Braille. Lappin and Foulke consequently studied the use of several fingertips simultaneously to see if information could be procesed more rapidly and accurately this way. Using eight subjects, four blind and four sighted, Lappin and Foulke had them identify the number of one-dot 
patterns in eight successive sets of four patterns, with one to four fingers on one or bot'i hands. The fastest reading times were obtained when the patterns were read by two fingers--one on each hand. The authors suggest that use of separate hands in reading Braille is a fertile topic for further exploration.

\subsubsection{Shape Sensitivity}

Some research has bee done on the tactile perception of alphanumeric and geometric shapes. Austin and Sleight (1952a) examined the accuracy of tactile discrimination for letters, numbers and geometric forms using the index fingertip. They were concerned with determining the maximum number of forms which could be accurately discriminated.

Two sets of stimulus figures were used in the experiment. The first set contained all the letters of the alphabet, the numbers 2-9, and geometric forms including a diamond, square, right triangle, equilateral triangle, rectangle, parallelogram, crescent, semicircle and cross. The first set were cut from $1 / 4$ inch masonite sheeting with each character being the maximum size that could fit within a $1 / 2$ inch circle. A constant stroke width of $2 \mathrm{~mm}$ was maintained from the letters and figures; the geometric forms were solid. In the second set the forms were made of wire pins. Thus the forms were made of a series of points. A total of 43 forms was tested in each of the two sets. Each set was mounted inside a circular wooden disc which allowed the experimenter to expose each form individually through a slit.

Subjects were asked to touch each form as it was presented and to respond as quickly as possible indicating to the experimenter what the form was. Both index fingers were used, alternating every five to ten trials. This procedure was followed for four conditions--solid forms with no hand movement, solid with movement, point figure with no movement, and point figures with movement. Ten adults, five male and five female were tested in each condition for a total of forty participants in the entire experiment.

The authors report their results in terms of a 90 percent accuracy criterion. Using this criterion, six letters, C, I, L, O, T, and U, were reported accurately for all four conditions. When no movement of the fingers was allowed, nine soiid and twelve point forms were accurately identified. Clearly movement of the fingers is critical for accurate discrimination. Thus, with solid forms and movement, almost 60 percent of the stimuli met the criterion. These included: $\mathrm{C}, \mathrm{D}, \mathrm{E}, \mathrm{G}, \mathrm{I}, \mathrm{J}, \mathrm{K}, \mathrm{L}, \mathrm{O}, \mathrm{P}, \mathrm{Q}, \mathrm{T}, \mathrm{U}, \mathrm{V}, \mathrm{W}, \mathrm{X}, \mathrm{Y}, \mathrm{2}, \mathrm{7}$, 9, diamond, right triangle, rectangle, crescent, and semicircle. Accuracy was not correlated with speed of response, however.

Analysis of the error data revealed that common confusions occurred among some letter pairs such as $\mathrm{T}$ and $7, \mathrm{Z}$ and $2, \mathrm{G}$ and $6, \mathrm{~B}$ and $8, \mathrm{~A}$ and an equilateral triangle, $C$ and 0 , and $S$ and 5 .

Using a combined criterion of both accuracy and speed, the authors recommend that ten forms can be selected which should be highly effective; namely, C, I, $\mathrm{V}, 0,7, \mathrm{~L}, \mathrm{U}, \mathrm{J}, \mathrm{D}$ and $\mathrm{E}$. These should be solid forms, and finger movement should be maximized. 
In a second experiment, Austin and Sleight (1952b) investigated some of the factors which might affect the speed and accuracy of tactile discriminations. These factors included sex, handedness, learning, fingertip pressure, and subjective confidence. The figures tested were those 25 which met the 90 percent accuracy criterion from the previous experiment.

Subjects again discriminated the shapes by touch, and also gave a rating of their confidence in their discrimination on a five point scale. Reaction time, confidence rating, exerted pressure, and answer were recorded for each of the 16 subjects. Eight men and eight women, half left-handed and half right-handed were tested. Subjects made 25 discriminations in each of the 8 trials.

Accuracy increased from 87.3 percent to 100 percent over trials, while reaction time decreased from 9.11 seconds to 3.52 seconds. Variability also decreased over time. Mean confidence ratings increased from 3.99 to 4.92 over trials. Pressure tended to be moderate at about 0-3 oz of pressure. Finally, sex, handedness, and finger did not affect either accuracy or reaction time data significantly. A short reaction time was highly correlated with high accuracy. Confidence ratings were more highly correlated with reaction time than with accuracy. The data indicate further that considerable learning occurred over trials, with all persons reaching 100 percent accuracy in short periods of training--for the 17 upper-case letters, 3 numerals and five geometric forms tested.

Craig (1979) compared confusion matrices for visually and vibrotactilely presented letters. The tactile letters were presented in a $1.1 \times 2.0 \mathrm{~cm}$ array on the subject's fingertip. The correlation between visual and tactile confusion matrices was rather strong, .88 , which "suggests that similar processes are involved in identifying letters presented via the two modalities" (Craig, 1979 , p. 409). These data may suggest strong similarities in processing between visual and tactile perception. (It is not clear whether sighted or blind subjects were used--congenitally blind subjects, being much less familiar with alphabetic characters, might not evidence the same sorts of confusions.)

Bradley (1967) investigated tactile coding of knobs using unique shapes. While knobs are perhaps less relevant to the communication needs of the disabeled, Bradley's research provides some insight into the parameters which determine distinctive coding shapes. Using rim surface, diameter, and thickness, as the major parameters, Bradley had subjects select one of two visual images which matched the "felt" knob. The knobs were felt both with and without gloves in a series of experiments which studied knob parameters. In brief, Bradley determined that 18 tactually indentifiable knobs could be constructed by using three different rim families--smooth, fluted or knurled--which varied in diameter by as much as $1 / 2$ inch and in thickness by as much as $3 / 8$ inch.

Use of gloves predictably impaired performance on the tactual discrimination-an impairment that was not erased by training. Limiting response time to one second also degraded performance.

These data suggest that a series of discrete, different knobs could be developed and used to code information for visually impaired people. Such 
a system would have to be learned, however, and does not appear to be any more effective than the geometric forms studied by Austin and Sleight (1952). Furthermore, the alphanumeric characters the latter authors studied can be used to form words, although it is not clear that any research has been done on the discriminability of words made from tactile alphanumeric shapes. Many visually impaired people are not necessarily familiar with the written alphabet (Aiello and Steinfeld, 1975) so that use of tactile words may not communicate as readily and effectively as a sighted, literate person might expect.

Although the characteristics of active touch have not been studied by extensive psychophysical research, various researchers have attempted to develop systems for using active touch to communicate to blind observers. Thus, Nolan and Morris (1971) suggest that tactile shapes must be a minimum of 0.2 in $(0.5 \mathrm{~cm})$ for successful discrimination. Schjif (1980) suggests that there are about 5-12 discriminable shapes usable as symbols on diagrams or maps. The following characteristics of point symbols appear to determine successful discrimination: number of points, narrow vs. wide spacing, open vs. closed, and points vs. no points--with these features being figure rather than background. Spacing between symbols is best if it is .09 in (2.3 mm) to 0.15 in ( $3.8 \mathrm{~mm}$ ) for discrimination of individual shapes. Although orientation is a critical cue for vision, Schiff (1980) suggests that it is an ineffective cue for haptic perceptions. Finally, Schiff (1980, p. 144) noted that "As with most isolated perceptual stimuli, some shapes for tactual percepton are quite discriminable from one another in pairs or in single contexts, but may lose their discriminability in other pairs or more complex contexts. It is important, therefore, to consider the context in which a tactual shape is being presented, since depending on the context, another shape may prove better." Schiff noted that Austin and Sleight found that only about eight letters were fully discriminable. As noted earlier, no one appears to have investigated the perception of words made from alphabetic shapes.

As well as point symbols, line symbols have also been investigated. Schiff (1980) reported that the critical characteristics of line symbols are: spacing vs. interruption, continuity vs. discontinuity, thickness, relief, smooth or rounded units vs. sharp units, and single versus double lines. Easton and Bentzen (1980) reported that simple line configurations were generally explored more rapidly and were more accurately represented mentally than double line configrations.

Shiff reported an experiment in which the characteristics of a tactile directional indicator, designed to convey the same kind of information as a visual arrow, were explored. In one scanning direction this indicator feels smooth, indicating "toward", while in the other it feels sharp, indicating "away from." Schiff commented (1980, p. 150) that "furthermore, directional information is available throughout the entire scan along the line, but not so with the visual arrow symbol. There may be more untapped ways of presenting information via the haptic-tactual system, providing one is not trapped by visual conventions or visual information."

A study of 8 areal texture and 17 line symbols by James and Gill (1975) indicated that about 10 discriminable tactile linear symbols exist, while 
only 5 discriminable areal symbols exist. Similarly, James and G111 (1974) determined that variations in symbol height can provide discriminable cues for map symbols. Gill (1974) reported that size, elevation, form (configuration) and orientation affect the discriminability of tactual symbols. He also reported research by Nolan indicating that students made 7 percent more errors and took 38 percent longer to read incised figures than raised figures.

Prieser and Brecht (1981) studied the discriminability of tactile symbols for use in building maps for the visually handicapped. They found that subjects could not accurately identify common building element symbols when first presented. Although the stair and carpet symbols appeared to be the most intuitively obvious, these were correctly indentified by only about one quarter of the subjects. Nevertheless, despite the lack of initial accurate identification of the 15 tactile symbols, these were learned in 5-6 trials, despite confusion between some symbols. Subsequent testing of these tactile symbols on a building wap proved disappointing, with subjects performing at a chance level of accuracy.

Edmondo and Macey (1968) asessed the effectiveness of tactile arrows in an overall evaluation of the lighting and directional signage systems aboard U.S. Navy ships for use in case of fire. Sighted subjects were tested in an actual non-toxic smoke environment in which visibility was extremely reduced. Time to escape through a maze, and number of errors were measured. The effectiveness of a battle lantern, xenon flash lamp, retroreflective tape and tactile arrows in guiding subjects through the maze were compared. The arrows were cut from pavement stripping with glass beads embedded in it providing a rough surface. The arrows were mounted six inches apart at two feet above the deck. The results indicated that performance was worst by a factor of two for the tactile arrows. The authors suggested that using the arrows to guide behavior is worse than no guidance at all, because of the difficulty of discriminating the arrows from the surrounding surface texture. Error scores were lowest for the tactile arrows, but the time to negotiate the maze was double that for the other signaling techniques. The authors did not assess different arrow configuration, textures, or the effects of training.

Finally, three-dimensional shapes have been investigated as coding elements. Again, the number of distinctly discriminable shape elements is small--between 8-10 (Schiff, 1980). Kirman (1973) suggested that the real problem in tactile perception arises because no display "permits the perceptual organization of linguistic units larger than the individual letter" (p. 68). Speed in visually reading a written passage is due to the readers' ability to organize input into large linguistic units beyond individual letters. Coding systems for the blind have relied upon conveying one letter at a time--a slow and inefficient way of processing information. Kirman (1973, p. 70) concluded that "While the visual system can integrate letter units into words and phrases by simultaneous spatial integration and while the auditory system relies solely on complex temporal integration, tactile displays can most effectively utilize spatio temporal integration as well as rhythmic temporal integration." Thus, a system in which successive stimuli can easily be integrated into easily perceptible units must be devised. Yet before an effective tactile display "can be properly designed, it is necessary to determine more specifically which temporal and spatiotemporal 
features of a tactile display most effectively meet the demands of perceptual distinctiveness and ingratability" (Kirman, 1973, p. 72).

\subsubsection{Tactile Door Marking}

Both the ANSI standard and the ATBCB ruIe provide for tactile door indicators to hazardous areas such as loading platforms, equipment rooms and the like. Table 7 summarizes these provisions as weli as those given in other codes. It should be noted that both the Illinois and GSA codes suggest tactile door knob markers for both emergency egress and hazard warnings. They do not specify how to differentiate one cue from the other, although confusion between these cues could lead to serious accidents. Furthermore, no researcher appears to have directly investigated the effectiveness of tactile markings on door knobs. Lederman and Taylor (1972) and Lederman (1974) reported various rough surfaces that could be discriminated. Schiff (1980) reported that various areal symbols could be discriminated by surface roughness, although he commented that the tactile system is a bit limited on this discrimination. As a result the characteristics of textured door knobs remain unspecified. Clearly, however, the potential for serious accidents is great if textured knobs are used to indicate both egress and warning.

There is a great need consequently to develop unique tactile cues for both hazard warnings on doors and for egress markings. These cues must, however, be immediately discriminable even to severely visually handicapped people with diabetes. 
Table 7. Tactile Warnings on Doors and Vertical Surface

\begin{tabular}{|c|c|}
\hline $\begin{array}{c}\text { ATBCB -- Rule } \\
1190.130-- \text { Doors }\end{array}$ & $\begin{array}{l}\text { ANSI A117.1-1980 } \\
4.29 \text { Tactile Warning }\end{array}$ \\
\hline $\begin{array}{l}\text { ( } g \text { ) Doors to hazardous areas. } \\
\text { Provide a textured surface on any } \\
\text { door handle, knob, pull, or other } \\
\text { piece of operating hardware on } \\
\text { doors that lead to areas that may } \\
\text { prove hazardous to blind people. } \\
\text { Such areas may include but are not } \\
\text { limited to, loading platforms, } \\
\text { mechanical equipment rooms, stages } \\
\text { and similar spaces. Textured sur- } \\
\text { faces may be achieved by knurling, } \\
\text { roughening, or applying materials } \\
\text { on the hand contact surface. Do } \\
\text { not provide textured surfaces on } \\
\text { hardware leading to emergency } \\
\text { egress or on any doors other than } \\
\text { those leading to hazardous areas. }\end{array}$ & $\begin{array}{l}\text { 4.29.3* Tactile Warnings on Doors } \\
\text { to Hazardous Areas. Doors that lead } \\
\text { to areas that might prove dangerous } \\
\text { to a blind person (for example, doors } \\
\text { to loading platforms, boiler rooms, } \\
\text { stages, and the like) shall be made } \\
\text { identifiable to the touch by a tex- } \\
\text { tured surface on the door handle, } \\
\text { knob, pull, or other operating hard- } \\
\text { ware. This textured surface may be } \\
\text { made by knurling or roughening or by } \\
\text { a material applied to the contact } \\
\text { surface. Such textured surfaces } \\
\text { shall not be provided for emergency } \\
\text { exit doors or any doors other than } \\
\text { those to hazardous areas. }\end{array}$ \\
\hline
\end{tabular}




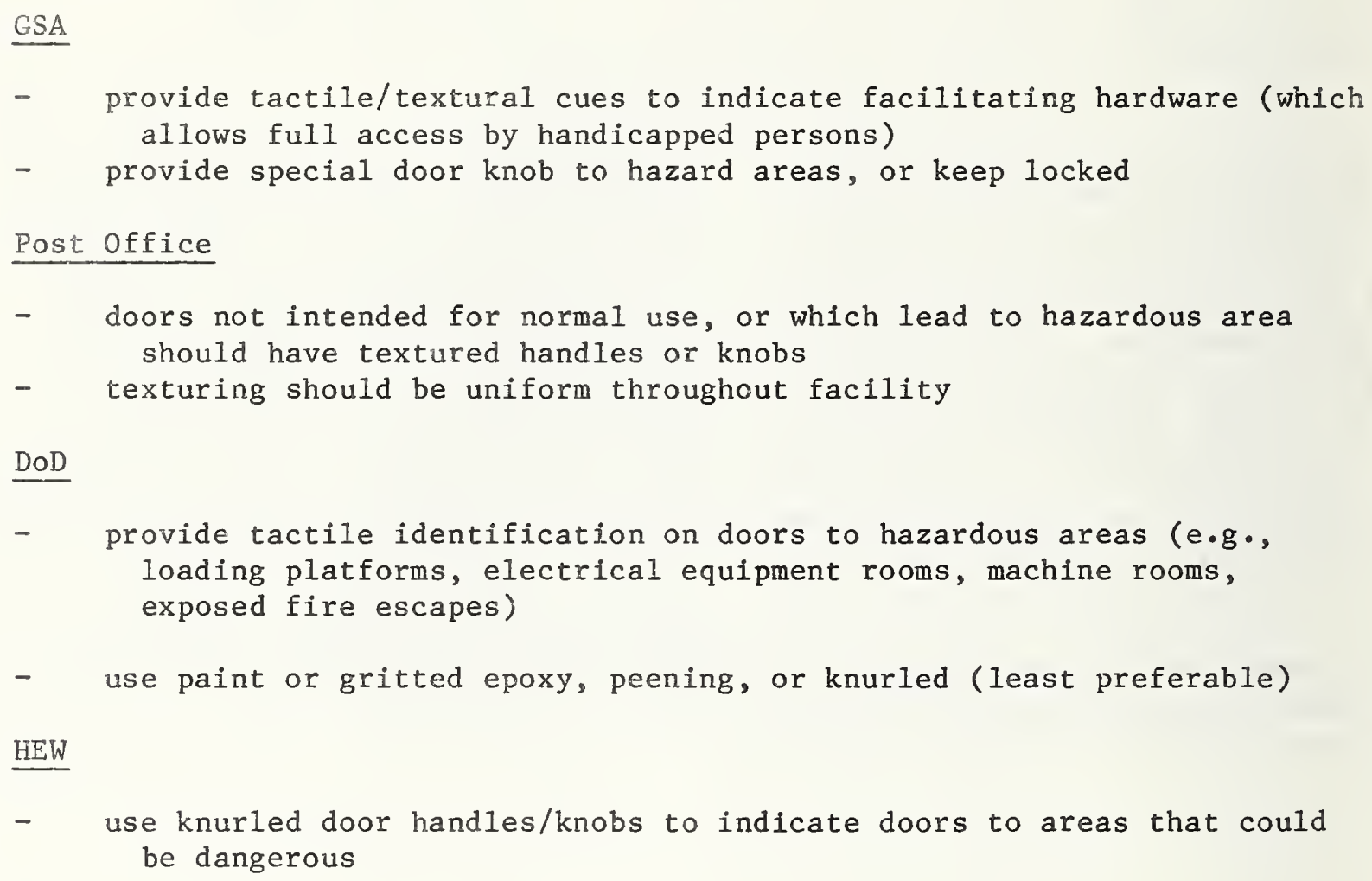

\section{Illinois}

- identify emergency exit manual door openers by tactile means surface should be roughened by knurling or applying abrasive finish -texture should be uniform in facility

- identify doors to hazardous areas with change in texture, such as knurling or abrasive finish

- tactile warnings should be located 4'-6" - 5'0" from floor

\section{New Jersey}

- doors to hazardous areas (boiler rooms, stages, fire escapes, loading platforms) shall have identifiable door handles or knobs

- hardware should be non-lever type, knurled or coated with abrasive (or have key-operated latch)

\section{North Carolina}

- doors to hazardous areas shall have knurled handles on knobs 


\section{Texas}

- doors not intended for normal use, or that might lead to hazardous areas shall be identifiable by knurling the door handle or knob

\section{Michigan}

- use knurled door knobs, handles, push bars to indicate doors leading to hazardous areas

$\underline{\text { Minnesota }}$ - UBC 5507

- doors leading to hazardous areas must have knurled or similarly marked door handles

\section{Washington}

- door handles or knobs on doors to stairs, loading platforms, stages, mechanical equipment rooms, fire escapes or other hazardous areas shall be knurled or otherwise rough.

Utah

- use knurled door handles, bars on knobs with integrally stamped knurling in hardware device to mark entrances to hazardous areas

\section{Australia}

- identify danger area - perhaps by knurling 
The preceding review of the research literature has suggested serious gaps in the knowledge base underlying the code provisions for tactile communication.

For tactile warnings for horizontal surfaces, the research appears to be limited to two major studies. Neither of these studies used a large number of visually impaired participants nor were the characteristics of the tactile surface varied parametrically to determine the best surface. Furthermore, even though variables such as footgear were not assessed, the limited findings disagreed about the size of the area to be identified. Clearly the determination of the characteristics of optimal tactile horizontal cueing systems has only begun.

There appears to be little research basis for specifying tactile warnings on doorknobs. No one has determined what physical characteristics might be optimal for warning people of hazardous areas beyond a door. The codes mention knurled or roughened surfaces; research suggests that such characteristics are detectable, but no one has actually assessed performance with such tactually marked knobs. Bradley's research suggests that there are at least three distinctive types of knob treatments which are discriminable. The issue then is to extend this research to the visually impaired (including the diabetic) to determine the physical characteristics that would be optimal for tactile communication.

With respect to informational and directional signage, the research base suggests that the dimensions recommended by ANSI A117.1 and the ATBCB rule are more than adequate for detection of a single letter (see table 5). The only studies investigating alphanumeric discriminability used $2 \mathrm{~mm}$ characters. The code recommendations of $16 \mathrm{~mm}$ to $50 \mathrm{~mm}$ height are well beyond this. Kenshalo (1978) suggested grooves of $1 \mu \mathrm{m}$ are detectable; the recommended incised/raised height of $0.8 \mathrm{~mm}$ is above this. The issue of spatial separation between characters, however, is not addressed by the codes. Heinrichs and Moorehouse (1969) recommend no less than $3.0 \mathrm{~mm}$ if diabetic blind observers are considered. Whether these proportions are optimum for detection is not clear from the limited research reviewed. Aiello and Steinfeld (1979) report that subjects found stroke widths of $1 / 16$ in to be too wide, for example.

Other issues such as the familiarity of visually handicapped people with printed (tactile) alphanumeric characters and optimum placement of tactile signs are also not addressed. In the existing codes use of symbolic presentation of spatial information and non-visual landmarks to guide the visually handicapped are not included, either. Consistent placement of tactile signs so that they can be readily found is as critical as the information on the sign (Leonard and Newman, 1970).

The final issue is that of tactile guidance for egress. The codes related to accessibility do not specify that exit routes be marked in any fashion tactile or otherwise. Yet NFPA 101 specifies clearly that exits be marked visually--a cue unavilable to visually handiapped users. There is, consequently, a great need to develop tactile exit signs and exit route markers to guide visually 
handicapped users through a building during emergencies (and normal conditions). As noted earlier, such cueing could serve the needs of those who are temporarily blinded due to smoke and fire. These cues must not be confused with those for hazard warnings, however.

\subsection{TACTILE RESEARCH NEEDS}

Although both types of tactile communication--directional information and hazard warning--require further research, the communication of hazard warning and emergency egress appears most critical due to the greater threat to life safety. The design of hazard warnings must be differentiated from that for emergency egress markings, to avoid confusions to the user - who urgently requires both kinds of information.

Future research should involve the parametric assessment of hazard warnings and egress indicators to be placed on horizontal surfaces and detected by foot or cane. It should expand the work done by Templer and Aiello and Steinfeld to include a directional egress marker such as that suggested by Schiff (1980). Handicapped users including the visually and mobility impaired should be used along with a control group of blindfolded nondisabled users. The latter group should be included to assess performance under temporarily disabling conditions. Characteristics of footgear and cane use must be assessed as well as those of the pavement/surface markers. The latter parameters include the area of the marked surface, distance from hazard, placement of egress markers, height (raise) of the marker, texture, pattern, resiliance, slip resistance, and contrast with surrounding materials. Behavioral characteristics such as gait, pace, stopping distance and cane use should be measured, along with the rated difficulty of detecting the marker. Personal observations and preferences should also be included. Consistent measures of the degree and kind of visual handicap must be obtained, along with demographic measures such as age, sex, education, movement experience and duration of handicap. For egress markers, the problem is to assess the characteristics of a series of tactile markers for their detectability and effectiveness in guiding behavior.

Once the design of the most effective cues for hazard warnings and egress markers on horizontal surfaces has been determined, the same problem must be researched for vertical surfaces such as doors. A set of immediately discriminable cues for warning and for egress must be developed and assessed for visually handicapped and other users. Furthermore, the design of more effective tactile signage, including specialized shapes, should be researched for visually handicapped users.

Experimental determination of the characteristics of effective tactile surface cues for both hazard warning and emergency egress guidance is essential. Such research is needed for providing the technical basis needed for decisions about code provisions to increase the accessibility of the built environment. 
In the previous sections the communication code requirements for each of three sensory modalities have been presented. The research base supporting each provision has been discussed, and recommendations for further research proposed.

A review of the preceding sections indicates that the research base underlying many of the provisions is inadequate. In many cases, the effectiveness of the proposed systems has not been sufficiently determined for either disabled or non-disabled users. This is particularly true in the tactile area, where not only is the research base insufficient, but the code provisions also overlook the critical issue of alerting for emergency egress.

Based upon the preceeding review of the research literature, several problem areas can be viewed as high priority for further research. These are summarized in table 8. Although communication systems are intended for both normal and emergency alerting, further assessment of emergency and hazard warning indicators is considered to be of highest priority. As a result, the quantification of the most effective design characteristics of tactile hazard warnings and emergency egress markers is one of the most important aspects of improving communication systems for disabled building users. As noted earlier, determination of more effective egress indicators can also aid all building users during emergency conditions when visibility is impaired. A second high priority area is the assessment of more effective visual alarms including further examination of flash rate, temporal patterning and general conspicuity of exit signs and emergency indicators. A third, related area is the determinnation of the characteristics of audible alarms for which temporal patterning, frequency, and intensity must be considered for disabled users.

Other communication areas requiring further research are related to the general accessibility and use of buildings. Direction finding within buildings can pose a significant problem for the visually impaired. The characteristics of visual and tactile signage require further delineation to determine their optimal characteristics. Use of tactile graphic symbols requires further exploration as a consideration for those who are not fluent in braille or alphanumeric characters, for example. Finally considerable research is needed on the design for improved speech intelligibility systems in buildings, which could form the basis of design recommendations for improving the acoustic characteristics of the built environment. 
Table 8. Recommended High Priority Areas for Research on Building Communication Systems for Disabled Users

1. Quantify characteristics of optimal tactile hazard warning markings for horizontal surfaces, walkways and doors. Determine properties of effective tactile markings for egress, and directional indicators for use during building emergencies.

2. Quantify conspicuity characteristics of more effective visual and acoustic alerting systems, including pulsed exit directional indicators and audible alarms.

3. Determine characteristics of combined tactile and visual markers for direction finding and information. Assess properties of symbolic and alphanumeric characters as well as combinations of both.

4. Provide design recommendations for improved systems speech intelligibility, alarms, and acoustic transmission in public assembly areas. 


\subsection{CODE REFERENCES}

\section{General}

American National Standard, A 117.1-1980, Specifications of Making Buildings and Facilities Accessible to and Usable by Physically Handicapped People. New York: American National Standards Institute, 1980.

Architectural and Transportation Barriers Compliance Board. Minimum Guidelines and Requirements for Accessible Design. 36 CFR Part 1190. Federal Register, $1981,46,4270-4304$.

\section{Federal Agency Documents}

U.S. Department of the Army, Office of the Chief of Engineers, Design for the Physically Handicapped, Manual No. 1110-103, Washington, D.C.: Government Printing Office, October 15, 1976.

U.S. General Services Administration, Public Building Service, Design Criteria: New Public Building Accessibility, Washington, D.C.: Government Printing Office, December 1977.

U.S. Department of Health, Education, and Welfare, Office of Facilities Engineering, Technical Handbook for Facilities Engineering and Construction Manual: Part 4-Facilities Design and Construction, Washington, D.C.: Government Printing Office, August 1978.

U.S. Postal Service Real Estate and Buildings Department, United States Postal Service Standards for Facility Accessibility for the Physically Handicapped, Washington, DC.: Government Printing Office, June 27, 1979.

\section{State Documents}

Commonwealth of Massachusetts, Department of Public Safety, Rules and Regulations

State of Illinois Capital Development Board, Accessibility Standards Illustrated, by M. A. Jones, Springfield, Illinois: The Capital Development Board, June 1978.

The University of Michigan, The Office of Disabled Student Services, Barrier Free Design: A Design Manual Code, by G. Selim, Ann Arbor: The University of Michigan, 1977 .

Kiewel, H., and Salmen, J., Accessible Architecture: An Illustrated Handbook Based on Minnesota State Building Code, 1977.

State of New Hampshire, Governor's Commission for the Handicapped, The Architectural Barrier Free Design Code for the State of New Hampshire, 1978. 
State of New Jersey, Department of the Treasury, Division of Building and Construction, Barrier-Free Design Regulations (for Providing Facilities for the Physically Handicapped in Public Buildings), 1977.

State of North Carolina, Governor's Study Committee on Architectural Barriers and the North Carolina Department of Insurance, An Illustrated Handbook of the Handicapped Section of the North Carolina State Building Code, by R. I. Mace, 1974 .

State of North Carolina, North Carolina Special office for the Handicapped, Department of Insurance, Accessibility Modifications: Guidelines for Modifications to Existing Buildings for Accessibility to the Handicapped, by R. I. Mace, Barrier Free Environments, 1976.

Ohio Governor's Committee on Employment of the Handicapped, and Schooley Cornelius Associates, Access for All: An Illustrated Handbook of Barrier Free Design for Ohio, 1977.

The University of Texas System, Office of Facilities Planning and Construction, Senate Bill No. 111 - Guidelines, by E. E. Farrera, September 1973.

Utah State Building Board, Planning and Design Criteria to Prevent Architectural Barriers for the Aged and Physically Handicapped, by E. H. Johnson, Fourth Edition, 1978 .

Sma11, Robert, and Allan, Barbara, An Illustrated Handbook for Barrier Free Design: Washington State Rules and Regulations, 1976.

\section{Foreign Documents}

Standards Association of Australia, Australian Standard 1428-1977: Design Rules for Access by the Disabled, North Sydney: Standards Association of Australia, 1977 .

\subsection{VISUAL COMMUNICATION REFERENCES}

1. U.S. Bureau of the Census. Statistical Abstract of the United States (100th edition). Washington, D.C.: U.S. Government Printing Office, 1979.

2. Murphy, J. How Does a Blind Person Get Around? New York: American Foundation for the Blind, Inc., 1975.

3. American Foundation for the Blind. Facts About Blindness. New York: Author, 1975.

4. Bartley; S. H. A Clarification of Some of the Procedures and Concepts Involved in Dealing with the Optic Pathway. In R. Jung and H. Kornhuber (eds.), The Visual System: Neurophysiology and Psychophysics. Berlin: Springer-Verlag, 1961 . 
5. Gerathewohl, S. J. Conspicuity of Steady and Flashing Light Signals: Variation of Contrast. J. Opt.Soc.Amer., 43 (7), 567 (1953).

6. Gerathewoh1, S. J. Conspicuity of Flashing Light Signals: Effects of Variation Among Frequency, Duration and Contrast of Signals. J. Opt. Soc. Amer., 47, (1), 27 (1957).

7. Crawford, A. The Perception of Light Signals: The Effect of the Number of Irrelevant Lights. Ergonomics, 4 (3), 47 (1962).

8. Crawford, A. The Perception of Light Signals: The Effect of Mixing Flashing and Steady Irrelevant Lights. Ergonomics, 6 (3), 287 (1963).

9. Wiley, A. E. High-rise Building Fire. Fire Journal, 66, 6 (1972).

10. Bryan, J. L. A Study of the Survivors Reports on the Panic in the Fire at the Arundel Park Hall in Brooklyn, Maryland on January 29, 1956. Unpublished report. College Park, Maryland: University of Maryland, 1956.

11. Howett, G. L., with Kelly, K. L., and Pierce, E. T. Emergency Vehicle Warning Lights: State of the Art. U.S. National Bureau of Standards Special Publication 480-16. Washington, D.C.: U.S. Government Printing office, September 1978.

12. Jeavons, P. and Harding, G. F. A. Photosensitive Epilepsy: Clinics Developmental Medicine (No 56). $19 \overline{75 .}$

13. Holmes, J. G. The Language of Flashing Lights. In The Perception and Application of Flashing Lights. Toronto: University of Toronto Press, 1971.

14. Meister, D. and Sullivan, D. J. Guide to Human Engineering Design for Visual Displays. Report prepared under Contract No. N00014-68-C-0278 for the Office of Naval Research, August 1969.

15. Heglin, H. J. NAVVSHIPS Display Illumination Design Guide: Section II, Human Factors. Technical document 223. San Diego, California: Naval Electronics Laboratory Center, July 1973.

16. Tinker, M. A. Legibility of Print. Ames, Iowa: University of Iowa Press, 1963.

17. Bishop, H. P. and Crook, M. H. Absolute Identification of Color for Targets Presented Against White and Colored Backgrounds. (WADD Technical Report 60-611). Wright Air Development Division, Wright-Patterson AFB, Ohio, March 1961. 
18. Hilgendorf, A. L. and Milenski, J. Effects of Color and Brightness Contrast on Target Acquisition. SEEKVAL Project 1A1. (AMRL-TR-74-55). Aerospace Medical Research Laboratory, Wright-Patterson AFB, Ohio, July 1974 .

19. Wagner, D. W. Target Acquisition with Color vs. Black and White Television. (NWC TP 5000). Naval Weapons Center, China Lake, Calif., October 1975 .

20. Roth, E. M. and Finkelstein, S. Light Environment: In Compendium of Human Responses to the Aerospace Environment (E. M. Roth, ed.). NASA Contractor Report NASA CR-1205-1, Washington, D.C., November 1968.

21. McLean, M. V. Brightness Contrast, Color Contrast and Legibility. Human Factors, 7, 521 (1965).

22. Illuminating Engineering Society of North America. IES Lighting Handbook (Reference volume). New York: Author, 1981.

23. Sorensen, R. J. Design for Accessibility. New York: McGraw-Hill, 1979.

\subsection{ACOUSTIC COMMUNICATION REFERENCES}

24. Anon., A proposed standard fire alarm signal, Fire Journal, July, 1975.

25. Anon., Hearing aids and audiometers, Medical Research Council, Special Report No. 261, H. M. Stationery Office, London, 1947.

26. Anon., IS0 389-1975(E), Acoustics - Standard reference zero for the calibration of pure-tone audiometers, International Organization for Standardization, 1975.

27. Anon., Life Safety Code, No. 101, 6-3141, National Fire Prevention Association, Boston, 1973.

28. Anon., National Fire Codes, Vol. 7, 6-3.1, National Fire Protection Association, Boston, 1976.

29. Anon., Uniform Building Code, Standard No. 43-6,

30. Beasley, W. C., Characteristics and distribution of impaired hearing in the population of the United States, J. Acoust. Soc. Am., 12, 114-121, 1940.

31. Beck, L. B., ed., Handbook of Hearing Aid Measurement 1980, Veterans Administration, Washington, D.C., 1980.

32. Butler, H., Sounding off, Building Services, April, 1980.

33. Corliss, E., Personal communication, 1981. 
34. Corso, J. F., Presbycusis as a complicatirg factor in evaluating noiseinduced hearing loss, in Effects of Noise on Hearing, Henderson et al., eds., Raven Press, N.Y., 1976.

35. Davis, D., Uses, abuses, and misuses of the critical distance concept, Syn-Aud-Con-Tech Topic, 7(12), 1-8, 1980.

36. Davis, D., and Davis, C., Sound System Engineering, Howard W. Sams and Company, Inc./The Bobbs-Merill Co., Inc., Indianapolis, Indianapolis, 1976.

37. Davis, H., et. al., (1947), Hearing Aids: An Experimental Study of Design Objectives, Harvard University Press, Cambridge, 1947.

38. Davis, J., (1974), Performance of young hearing-impaired children on a test of basic concepts, J. Speech Hear, Res., 17, 342-351, 1974.

39. Duequesnoy, A. J., and Plomp, R., Effect of reverberation and noise on the intelligibility of sentences in the case of presbyacusis, J. Acoust. Soc. Am., 68(2), 537-544, 1980 .

40. Egan, M. D., (1978), Concepts in Building Fire Safety, John Willey and sons, New York, 1978.

41. Finitzo-Heiber, T., and Tillman, T. W., (1978), Room acoustics effects on monosyllabic word discrimination ability for normal and hearingimpaired children, J. Speech Hear. Res., 21, 440-458, 1978.

42. Green, D. M•, et al., (1975), A proposed standard fire-alarm signal, Committee on Hearing and Bioacoustics and Biomechanics, J. Acous. Soc. Am. , 57(3), 756-757, 1975.

43. Houtgast, T., Indoor speech intelligibility and indoor noise level criteria, in Proceedirigs of the Third International Congress on Noise as a Public Health Problem, ASHA Report 10, The American Speech-LanguageHearing Assoc., 1980.

44. Houtgast, T., and Steeneken, H. J. M., The modulation transfer function in room acoustics as a prediction of speech intelligibility, Acustica, $28,66-73,1973$.

45. Houtgast, T., Steeneken, H. J. M., and Plomp, R., Predicting speech intelligibility in rooms from the modulation transfer function. I. General room acoustics, Acustica, 46, 60-72, 1980.

46. Jensen, R., ed., Fire Protection for the Design Professional, Calmers Books, 1975.

47. Klein, W., Articulation loss of consonants as a basis for the design judgment of sound reinforcement systems, J. Audio Eng. Soc., 19(11), 920-922, 1971. 
48. Kurtovic, H., The influence of reflected sound upon speech intelligibility, Acustica, 33, 32-39, 1975.

49. Laney, M. D., The prevelence of communication disorders: A review of the literature, Am. Speech-Language-Hearing Assoc., Rockville, Maryland, 1980.

50. Lattam, H. G., The signal-to-noise ratio for speech intelligibility -an auditorium acoustics design index, Applied Acoust. 12(4), 252-320, 1979.

51. Lawrence, A. B., Architectural Acoustics, Applied Science Publishers, Ltd., London, 1980.

52. Martin, M. C., Communication systems for deaf people: A review of possibilities, J. Med. Eng. Technol., January, 16-19, 1977.

53. Maxfield, J. P. and Albersheim, W. J., An acoustic constant of enclosed spaces correlatable with their apparent liveness, J. Acoust. Soc. Am., 19(1), 71-79, 1947 .

54. Nabelek, A. K. and Pickett, J. M., Reception of consonants in a classroom as affected by monaural and binaural listening, noise, reverberation and hearing aids, J. Acoust. Soc. Am., 56(2), 628-639, 1974.

55. Nabelek, A. K. and Pickett, J. M., Monaural and binaural speech perception through hearing aids under noise and reverberation with normal and hearing-impaired listeners, J. Speech Hear. Res., 17, 724-739, 1974.

56. Northicott, W., The hearing impaired child in a regular classroom, The Alexander Graham Bell Association, Washington, D.C., 1973.

57. Peutz, V. M. A., Articulation loss of consonants as a criterion for speech transmission in a room, J. Audio Eng. Soc., 19(11), 915-919, 1971.

58. Peutz, V. M. A., Speech reception and information, Syn-Aud-Con-Tech Topic, $\underline{5}(12), 1-5,1978$.

59. Plomp, R., Auditory handicap of hearing impairment and the limited benefit of hearing aids, J. Acoust. Soc. Am., 63(2), 533-549, 1978 .

60. Plomp, R., Binaural and monaural speech intelligibility of connected discourse in reverberation as a function of azimuth of a single competing sound source (speech or noise), Acustica, 34, 200-211, 1976.

60. Plomp, R. and Duquesnoy, A. J., Room acoustics for the aged, Acustica, in press. 
5i. Plomp, R. and Mimpen, A. Mo, Improving the reliability of testing the speech reception threshold for sentences, Audiology, 18, 43-52, 1979.

52. Plomp, R. and Mimper, A. M., Speech-reception threshold for sentences as a function of age and noise leve1, J. Acoust. Soc. Am., 66(5), 1333-1342, 1979.

63. Plomp, R., Steeneken, H. J. M., and Houtgast, T., Predicting speech intelligibility in rooms from the modulation transfer function. II. Mirror image computer model applied to rectangular room, Acustica, 46 , $73-81,1980$.

64. Puzyna, C., Investigation of the barrier perception mechanisms of the blind, Archives of Acoustics (Warsaw), 4(2), 89-107, 1979.

65. Richardson, E. G. and Meyer, E., Technical aspects of sound, Vol. III, Recent Developments in Acoustics, Elsevier Publishing Company, New York, 1962 .

66. Steel, L., Inventory of communication barriers, 1980.

67. Steeneken, H. J. M., and Houtgast, T., A physical method for measuring speech-transmission quality, J. Acoust. Soc. A., 67(1), 318-326, 1980 .

.4 TACTILE COMMUNICATION REFERENCES

68. Austin, T. R. and Sleight, R. B., Accuracy of Tactual Discrimination of Letters, Numerals, and Geometric Forms. Journal of Experimental Psychom logy, 1952, 43, 239-247.

69. Austin, T. R. and Sleight, R. B., Factors Related to Speed and Accuracy of Tactual Discrimination. Journal of Experimental Psychology, 1952, $44,283-287$.

70. Bradley, J. V., Tactual Coding of Cylindrical Knobs. Human Factors, 1967, 9, 483-496.

71. Craig, J. C., A Confusion Matrix for Tactually Presented Letters. Perception and Psychophysics, 1979, 26, 409-411.

72. Easton, R. D. and Bentzen, B. L., Perception of Tactile Route Configuration uration by Blind and Sighted Absences. Visual Impairment and Blindness, $1980,74,254-265$.

73. Geldard, F. A., Pattern Perception by the Skin. In D. R. Kenshalo (ed.). The Skin Senses. Springfield, 211: Charles C. Thomas, 1968, PP. $304-321$.

74. Geldard, A. The Human Senses (2nd ed.). New York: Wiley, 1972. 
75. Genensky, S. M. Architectural Barriers to the Partially Sighted and Solutions. Architectural Record, 1980, May, pp. 65 \& 67.

76. Gill, J. M. Tactual Mapping, American Foundation for the Blind, Research Bulletin, 28, 1974, 57-80.

77. Hahn, J. F., Tactile Adaptation. In D. R. Kenshalo (ed.). The Skin Senses. Springfield, IL: Charles C. Thomas, 1968, pp. 195-222.

78. Heinrichs, R. W. and Moorhouse, J. A., Touch-perception Thresholds in Blind Diabetic Subjects in Relation to the Reading of Braille Type. The New England Journal of Medicine, 1969, 280, pp. 72-75.

79. Heller, M. A. Reproduction of Tactually Perceived Forms. Perceptual and Motor Skills, 1980, 50, 943-946.

80. James, G. A. and Gill, J. M., Mobility Maps for the Visually Handicapped: A Study of Learning and Retention of Raised Symbols. American Foundation for the Blind; Research Bulletin, 1974, 27, 87-98.

81. James, G. A. and Gill, J. M., A Pilot Study on the Discriminability of Tactile Areal and Line Symbols for the Blind. American Foundation for the Blind; Research Bulletin, 1975, 29, 23-31.

82. Kenshalo, D. R., Biophysics and Psychophysics of Feeling. In Carterette, E. C. and Friedman, M. P. (Eds.). Handbook of Perception, Vol. V1B. New York: Academic Press, 1978, pp. 30-74.

83. Kirman, J. H. Tactile Communication of Speech. Psychological Bulletin, $1973,80,54-74$.

84. Lappin, J. S. and Foulke, B. Expanding the Tactual Field of View. Perception and Psychophysics, 1973, 14, 237-241.

85. Lassen, P. and Berry, J. Signing for the Handicapped. Signs of the Times, 1979, August, 40-46.

86. Lawrence, D. M., Cobb, N. J., Beard, J. I. Influence of Active Encoding for Common Objects. Perceptual and Motor Skills. 1978, 47, 596-598.

87. Lederman, S. J. Tactile Roughness of Grooved Surfaces: The Touching Process and Effects of Macro- and Microsurface Structures. Perception and Psychophysics, 1974, 16, 385-395.

88. Lederman, S. J. and Taylor, M. M. Fingertip Force, Surface Geometry, and the Perception of Roughness by Active Touch. Perception and Psychophysics, 1972, 12, 401-408. 
89. Lindblom, U. and Lindstrom, B. Tactile Thresholds of Normal and Blind Subjects on Stimulation of Finger Pads with Short Mechanical Pulses and Variable Amplitude. In Y. Zotterman (ed•). Sensory Functions of the Skin in Primates. Piew York: Pergamanon Press, 1976, pp. 105-112.

90. Preiser, W. F. E. and Brecht, M. Design and Evaluation of a Tactile Building Directory for the Visually Handicapped. Design Research Interaction. Proceedings of the Twelfth International Conference of the Environmental Design Research Association, 1981, pp. 285-293.

91. Schif, W. Perception: An Applied Approach. Boston: Houghten Mufflin Co., 1980, pp. 109-163.

92. Stevens, J. C. and Green, B. G. History of Research on Feeling. In E. C. Carterette and M. P. Friedman (Ed.). Handbook of Perception, Vol. 118. New York: Academic Press, 1978, pp. 3-25.

93. Templer, J. A. Provisions for Elderly and Handicapped Pedestrians. Vol. 3. The Development and Evaluation of Counter Measures. FHWA$\mathrm{RD}-79-3$, May 1980.

94. Weinstein, S. Intensive and Extensive Aspects of Tactile Sensitivity as a Function of Body Part, Sex, and Laterality. In D. R. Kenshale, (Ed.). The Skin Senses. Springfield, IL: Charies C. Thomas, 1968, pp. 195-222.

95. White, B. W., Saunders, F. A., Scadden, L., Bach-y-Rita, P., and Collins. C. C. Seeing with the Skin. Perception and Psychophysics, 1970, 7, 2327.

96. Illuminating Engineering Society (I.E.S.). Calculating the Effective Intensity of Flashing Lights. Illuminating Engineering, 1964, Nov•, p. 747 . 
BIBLIOGRAPHIC DATA

SHEET (See instructions)

1. PUBLICATION OR

REPORT NO.

NBSIR $81-2428$

4. TITLE AND SUBTITLE

Communication Requirements for Disabled Users of Buildings

5. $A \cup T H O R(S)$

Belinda I. Collins, William F. Danner, Robert I. Tibbott

6. PERFORMING ORGANIZATION (If joint or other than NBS, see instructions)

NATIONAL BUREAU OF STANDARDS

DEPARTMENT OF COMMERCE

WASHINGTON, D.C. 20234

7. Contract/Grant No.

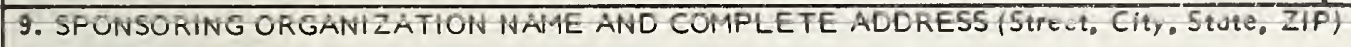

Architectural and Transportation

Barriers Compliance Board

330 C Street, S.W.

Washington, D.C. 20202

10. SUPPLEMENTARY NOTES

[D Document describes a computer program; SF-185, FIPS Software Summary, is attached.

11. ABSTRACT (A 200-word or less factual summary of most significant information. If document includes a significant bibliography or literature survey, mention it here)

Communication systems in buildings are designed to provide both emergency and directional information to all building users. Yet such systems, which are typically comprised of visual signs and audible alarms, may fail to reach some of the estimated twenty-seven million hearing or vision impaired people in the United States. As a result, a number of alternative communication systems have been proposed for inclusion in accessibility guidelines. In the following pages the research base underlying communication provisions for each of three sensory modalities, vision, hearing and touch, are reviewed. In addition, various proposed code recommendations are presented and discussed. The adequacy of the research base for each provision is discussed along with the need for various code provisions. It is noted that code provisions for tactile warnings and exit markings are particularly inadequate. Recommendations for further research into tactile warnings, tactile signage, and visual alarms are suggested.

12. KEY WORDS (Six to twelve entries; alphabetical order: capitalize only proper names; and separate key words by semicolons) Accessibility; alarms; blind; communication; code requirements; deaf; directional indicators; handicapped users; tactile warnings.

13. AVAILABILITY

[x] Unlimited

$\square$ For Official Distribution. Do Not Release to NTIS

[X] Order From Superintendent of Documents, U.S. Government Printing Office, Washington, D.C. 20402.

[_] Order From National Technical Information Service (NTIS), Springfield, VA. 2216I
14. NO. OF PRINTED PAGES

74

15. Price

8.00 

